\title{
Ozone, carbon monoxide and nitrogen oxides time series at four alpine GAW mountain stations in central Europe
}

\author{
S. Gilge ${ }^{1}$, C. Plass-Duelmer ${ }^{1}$, W. Fricke ${ }^{1}$, A. Kaiser ${ }^{2}$, L. Ries ${ }^{3}$, B. Buchmann ${ }^{4}$, and M. Steinbacher ${ }^{4}$ \\ ${ }^{1}$ Hohenpeissenberg Meteorological Observatory, German Meteorological Service (DWD), Hohenpeissenberg, Germany \\ ${ }^{2}$ Central Institute for Meteorology and Geodynamics (ZAMG), Vienna, Austria \\ ${ }^{3}$ Federal Environment Agency (UBA), Zugspitze, Germany \\ ${ }^{4}$ Swiss Federal Laboratories for Materials Science and Technology (EMPA), Duebendorf, Switzerland
}

Received: 23 June 2010 - Published in Atmos. Chem. Phys. Discuss.: 11 August 2010

Revised: 23 November 2010 - Accepted: 3 December 2010 - Published: 23 December 2010

\begin{abstract}
Long-term, ground based in-situ observations of ozone $\left(\mathrm{O}_{3}\right)$ and its precursor gases nitrogen dioxide $\left(\mathrm{NO}_{2}\right)$ and carbon monoxide (CO) from the four sites Hohenpeissenberg and Zugspitze (D), Sonnblick (A) and Jungfraujoch (CH) are presented for the period 1995-2007. These Central European alpine mountain observatories cover an altitude range of roughly 1000 to $3500 \mathrm{~m}$. Comparable analytical methods and common quality assurance (QA) procedures are used at all sites. For $\mathrm{O}_{3}$ and $\mathrm{CO}$, calibration is linked to primary calibrations $\left(\mathrm{O}_{3}\right)$ or CO standards provided by the Central Calibration Laboratory (CCL) at NOAA/ESRL. All stations have been audited by the World Calibration Centre (WCC) for $\mathrm{CO}$ and $\mathrm{O}_{3}$ (WCC-Empa; $\mathrm{CH}$ ). Data from long-term measurements of $\mathrm{NO}_{2}$ and $\mathrm{CO}$ are only available from Hohenpeissenberg and Jungfraujoch. Both sites show slightly decreasing mixing ratios of the primarily emitted $\mathrm{NO}_{2}$ and the partly anthropogenically emitted $\mathrm{CO}$ between 1995 and 2007. The findings are generally consistent with shorter observation periods at Zugspitze and Sonnblick and thus are considered to represent regional changes in Central European atmospheric composition at this altitude range. Over the same period, 1995-2007, the $\mathrm{O}_{3}$ mixing ratios have slightly increased at three of the four sites independent of wind sector. Trends are often more pronounced in winter and less in summer; highest declines of $\mathrm{NO}_{2}$ and $\mathrm{CO}$ are observed in winter and the lowest in summer, whereas the strongest $\mathrm{O}_{3}$ increase was detected in winter and lowest or even decline in summer, respectively. Weekly cycles demonstrate anthropogenic impact at all elevations with enhanced $\mathrm{NO}_{2}$ on working days compared to weekends. Enhanced $\mathrm{O}_{3}$
\end{abstract}

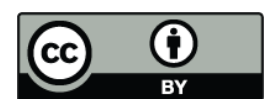

Correspondence to: S. Gilge (stefan.gilge@dwd.de) values on working days indicating photochemical production from anthropogenic precursors are only observed in summer, whereas in all other seasons anti-correlation with $\mathrm{NO}_{2}$ was found due to reduced $\mathrm{O}_{3}$ values on working days. Trends are discussed with respect to anthropogenic impacts and vertical mixing. The observed trends for $\mathrm{NO}_{2}$ at the alpine mountain sites are less pronounced than trends estimated based on emission inventories.

\section{Introduction}

The importance of atmospheric chemistry for weather, climate and air quality has been addressed by the World Meteorological Organisation (WMO) in their Global Atmosphere Watch (GAW) programme, established in 1989. Since that time, GAW has evolved into a major programme in the context of WMO's leading efforts to implement an Integrated Global Atmospheric Chemistry Observations (IGACO) strategy and the monitoring needs for essential climate variables like ozone, aerosols and greenhouse gases (WMO GAW Strategic Plan, 2007). To better understand climate change, GAW is devoted to changes in the chemical composition of the atmosphere. Reactive gases are recognized as precursors of ozone and aerosol and thus an understanding of the trends requires analyses of the respective precursor gases. The primarily emitted nitrogen oxides $\left(\mathrm{NO}_{\mathrm{x}}=\mathrm{NO}+\mathrm{NO}_{2}\right)$ have a substantial impact on radical chemistry, ozone $\left(\mathrm{O}_{3}\right)$ formation and aerosol by their atmospheric oxidation to aerosol nitrate. Carbon monoxide $(\mathrm{CO})$ is mostly primarily emitted from combustion processes, but it is also formed in substantial amounts from the oxidation of methane $\left(\mathrm{CH}_{4}\right)$ and volatile organic compounds (VOCs). Due to its high global

Published by Copernicus Publications on behalf of the European Geosciences Union. 
turn-over rates $\mathrm{CO}$ is a major $\mathrm{O}_{3}$ precursor, and it has a strong impact on the oxidizing capacity and thus indirectly on the concentration of the climate gas $\mathrm{CH}_{4} . \mathrm{O}_{3}$ is a climate gas itself, however, also strongly involved in $\mathrm{NO} / \mathrm{NO}_{2}$ partitioning and oxidizing capacity, thus coupling back on several photochemical processes. Accordingly, impacts on climate are multiple and rather complex. An understanding, however, requires high quality, long-term observations of these reactive species.

Trends in atmospheric composition over Europe with respect to $\mathrm{NO}_{2}, \mathrm{CO}$ and $\mathrm{O}_{3}$ have been analyzed in several recent papers. The primary, anthropogenic emissions in Europe-27 have declined substantially from 1995 to 2007 for most compounds: for $\mathrm{NO}_{\mathrm{x}}$ by $24.7 \%(-1.9 \% / \mathrm{yr})$, for $\mathrm{CO}$ by $44.5 \%(-3.4 \% / \mathrm{yr})$, and for NMVOC by $-33.6 \%$ $(-2.6 \% / y r)$ (EEA, 2009 (2)). Accordingly, the mixing ratios of $\mathrm{NO}_{2}$ from several monitoring stations and national networks showed downward trends of typically 0-6\%/yr (Jonson et al., 2006, Brönnimann et al., 2002, Jenkin, 2008), and for CO of typically 1-3\%/yr (Chevalier, 2008; Zellweger et al., 2009; Dils et al., 2009). For the long-lived CO with a life-time of 1-2 months, hemispheric impacts on the mixing ratios have been identified which include industrial and biomass burning emissions from the Asian and North American continents (Pfister et al., 2004, Zellweger et al., 2009, Yurganov et al., 2004 and 2005, Novelli et al., 2003). The relative source contribution of long-range transport grows with increasing elevation (Pfister et al., 2004). Recent detailed analysis of highly time resolved measurements in North America have indicated lower sources related to fossil fuel combustion and higher sources from VOC oxidation than previously assumed (Miller et al., 2008). Trends of ozone have been analyzed in multiple papers. For remote European sites continuous increases until the 1980s or 1990s have been identified, thereafter levelling off with weak, often non-significant trends both positive and negative (e.g. Oltmans et al., 2006; Vingarzan, 2004; Jenkin, 2008; Zbinden et al., 2006). Generally, the findings were interpreted by increasing background, decreasing losses in the vicinity of anthropogenic sources due to reduced NO titration, and less intensive photo-chemical production during summer smog episodes. Positive gradients with altitude are well established and are mainly due to higher loss by NO titration and deposition effects close to the ground and stratospheric impact at high altitudes (Chevalier et al., 2007; Brönnimann et al., 2000; Zbinden et al., 2006).

At first view, the observation of rather constant $\mathrm{O}_{3}$ mixing ratios at surface sites during the end of the 1990s to 2007 was surprising with respect to the substantial reductions in anthropogenic emissions. Accordingly, papers address the question if the observed $\mathrm{O}_{3}$ trends can be understood (e.g. Jonson et al., 2006). A recent comprehensive comparison of $\mathrm{O}_{3}$ observations with results from a photochemical model even showed that the largest discrepancies between measured and modelled trends were found in Switzer- land and Austria (EEA, 2009a). Obviously, trends in $\mathrm{O}_{3}$ and precursors are small and analyzing them requires high quality data with uncertainties of less than the observed trends, e.g. in the very low \%-range for $\mathrm{CO}$ and $\mathrm{NO}_{2}$, and in the sub- $\%$ range for $\mathrm{O}_{3}$. In addition, monitoring stations have to be representative for larger area (e.g. Central Europe), mapping emissions from this relevant area, but should not be influenced by local emissions, which would lead to an overestimation of the respective trace gas.

The Alpine GAW mountain stations Zugspitze (ZUG/ZSF) and Hohenpeissenberg (HPB) (Germany), Sonnblick (SNB) and Jungfraujoch (JFJ) have formed the three-nations DACH cooperation (Germany: D, Austria: A, and Switzerland: $\mathrm{CH}$ ). All stations operate rather comprehensive measurement programmes of gas and aerosol parameters together with meteorological observations (see http://gaw.empa.ch/gawsis/). The four stations are fairly close to each other, cover an altitude range of 1000-3600 m and due to their character as mountain sites they are only moderately affected by local anthropogenic emissions. Thus, combining the four sites principally enables us to separate local and regional effects and provide data more or less influenced by the surface, and in some cases representative, for certain time and space scales, of the free troposphere at similar altitude levels above the surrounding lowlands. This paper presents the long time series of ozone, carbon monoxide and nitrogen dioxide from the four DACH stations and investigates their consistency. Such quality assured data provide essential information for trend evaluation and model validation. In this paper we will not apply filter functions to distinguish between different air mass impacts like, e.g. free troposphere air, as filters depend on the station characteristics and thus can not be unambiguously applied to all stations. The focus of the paper is on data presentation and a general discussion of the similarities and differences of the four station's time series with respect to long term changes.

\section{Experimental}

\subsection{Stations}

A short description of the site characteristics and the measurement procedures is provided in this section. Table 1 lists the geographic locations and elevations. Up-to-date information is available under GAWSIS (http://gaw.empa.ch/gawsis/ default.asp) and on the corresponding web pages given in the text below.

Hohenpeissenberg together with Zugspitze started in 1994 as a German contribution to the Global Atmosphere Watch (GAW) programme of WMO. The GAW Zugspitze station is operated by the German Federal Environment Agency (UBA). Measurements are made in the Environmental Research Station "Schneefernerhaus" (ZSF) which is situated 
Table 1. Locations of the four DACH sites.

\begin{tabular}{llrlll}
\hline Station (Short name) & Latitude & Longitude & Altitude & Country & Institution \\
\hline Hohenpeissenberg (HPB) & $47^{\circ} 63^{\prime} \mathrm{N}$ & $11^{\circ} 01^{\prime} \mathrm{E}$ & $985 \mathrm{~m}$ & Germany & DWD \\
Hoher Sonnblick (SNB) & $47^{\circ} 03^{\prime} \mathrm{N}$ & $12^{\circ} 57^{\prime} \mathrm{E}$ & $3105 \mathrm{~m}$ & Austria & ZAMG/EAA \\
Jungfraujoch (JFJ) & $46^{\circ} 33^{\prime} \mathrm{N}$ & $7^{\circ} 59^{\prime} \mathrm{E}$ & $3580 \mathrm{~m}$ & Switzerland & Empa \\
Zugspitze (ZUG/ZSF) & $47^{\circ} 42^{\prime} \mathrm{N}$ & $10^{\circ} 98^{\prime} \mathrm{E}$ & $2962 / 2670 \mathrm{~m}$ & Germany & UBA \\
\hline
\end{tabular}

on the southern slope of Zugspitze at $2670 \mathrm{~m}$ elevation, right between the summit and the skiing area (Zugspitzplatt). In the first years (until 2001), measurements were performed in a laboratory at the summit building (2962 m) (ZUG) (see: http://www.schneefernerhaus.de/e-ufs.htm).

The Hohenpeissenberg GAW site (HPB) is operated by the German Meteorological Service (DWD) and has a history of continuous weather observations since 1781. HPB is on top of Hohenpeissenberg Mountain at $985 \mathrm{~m}$ elevation, which is about $300 \mathrm{~m}$ above the surrounding and fairly flat countryside. It is an isolated mountain about $30 \mathrm{~km}$ north of the first ridge (elevation up to $1800 \mathrm{~m}$ ) of the Alpine mountains. Different from the other stations in this study, HPB is usually inside the boundary layer during daytime, whereas at night and occasionally in winter also during daytime, it is above the boundary layer and exposed to residual layer air. Hohenpeissenberg is $40 \mathrm{~km}$ north of Zugspitze, and $60 \mathrm{~km}$ southwest of the city of Munich. Also different from the highalpine stations, there are forests close-by on the mountain slopes and in the surrounding area, and a road goes up to the site right from the east. More information can be found on the web (http://www.dwd.de/gaw) or in recent publications, e.g. Mannschreck et al. (2004).

The Jungfraujoch GAW site (JFJ, CH) is situated at $3580 \mathrm{~m}$ a.s.1. in the Swiss Alps on a saddle between the two mountains Jungfrau (4158 m) and Mönch (4099 m). JFJ is formally operated by the International Foundation "High Alpine Research Stations Jungfraujoch and Gornergrat HFSJG" founded in 1930. In-situ trace gas measurements are carried out by Empa (Swiss Federal Laboratories for Materials, Science and Technology). The site is a station of the Swiss National Air Pollution Monitoring Network (NABEL, since 1980), a primary NDACC (Network for the Detection of Atmospheric Composition Change), and a global GAW site. Jungfraujoch is the highest of the four sites considered here (more information: http://www.hfsjg.ch/jungfraujoch/).

The GAW regional site SNB (a GAW regional site is generally characterized by a less complete measurement programme and less scientific programme accompanying the GAW measurements compared to a global site, see ftp://ftp.wmo.int/Documents/PublicWeb/arep/gaw/ gaw172-26sept07.pdf) is on top of the Hoher Sonnblick $(3105 \mathrm{~m})$. Air masses from all directions can reach the site without being channelled by topography above the station altitude. The site is surrounded by glaciers, the valley is at $1600 \mathrm{~m}$ elevation and no major local anthropogenic activities impact the site as no tourist cable cars exist. The GAW site is operated by the Austrian Meteorological Service (ZAMG), measurements of gas phase parameters are contributed by the Environment Agency Austria (EAA), and university institutes (information at: http://www.sonnblick. net/portal/content/view/53/233/lang,en/ or www.zamg.ac.at/ sonnblickverein/projekte.html).

\subsection{Measurements of $\mathrm{O}_{3}, \mathrm{CO}$ and $\mathrm{NO}_{2}$}

All stations carry out long-term measurements of comprehensive sets of atmospheric constituents in gas and aerosol phase together with meteorological parameters (see web pages given above). $\mathrm{O}_{3}, \mathrm{CO}$, and $\mathrm{NO}_{2}$ are measured by different instruments (overview in Table 2), additional metadata is provided at the world data centre for greenhouse gases and related gases (http://gaw.kishou.go.jp/wdcgg/).

Ozone is measured by UV absorption at all stations, with TEI 49C (Thermo Electron Corporation, Environmental Instruments) analyzers in recent years. For $\mathrm{O}_{3}$ and $\mathrm{CO}$, all stations follow the guidelines by WMO-GAW (GAW-Report No.: 143), and have been audited by the World Calibration Centre for $\mathrm{O}_{3}$ and $\mathrm{CO}$ (WCC-Empa, $\mathrm{CH}$ for $\mathrm{O}_{3}, \mathrm{CO}, \mathrm{CH}_{4}$ and $\mathrm{CO}_{2}$ ). Uncertainties are listed in Table 2.

Carbon monoxide (CO) has been measured by nondispersive IR absorption photometry (NDIR), mostly by Thermo Environmental Instruments (Table 2). As there is a well characterized interference with water vapour for NDIR instruments, these instruments have either to correct for or to avoid this interference. Accordingly, at HPB a NDIR analyser dedicated to low ambient mixing ratios (TE $48 \mathrm{~S}$ ) is used with switching the sample gas every ten minutes between ambient air and zero air, which is ambient air with $\mathrm{CO}$ removed by means of a $\mathrm{Pd}$ catalyst at $150^{\circ} \mathrm{C}$, according to Parrish et al. (1994). CO measurements at JFJ are performed with NDIR instruments from Horiba (APMA-360, APMA370 since June 2007) that use cross flow modulation to compensate for matrix effects in the absorption measurements. There, the air passes over a heated oxidation catalyst to selectively remove $\mathrm{CO}$ from the sample air with a frequency of $1 \mathrm{~Hz}$. In addition, CO concentrations at JFJ are also measured with the GC-HgO technique (since August 2005) and 
Table 2. Measurement techniques, calibration, and uncertainty of measurements.

\begin{tabular}{|c|c|c|c|c|c|}
\hline station & parameter & Method/Instrument & Calibration & Audit/Reference & Uncertainty \\
\hline \multirow[t]{3}{*}{ HPB } & $\mathrm{O}_{3}$ & $\begin{array}{l}\text { 01/71-12/86: Potassium Iodide } \\
\text { (self built) 01/87-06/88: CLD } \\
\text { (Monitor Labs) 06/88-12/96: } \\
\text { UV abs. (Dasibi) since 10/92: } \\
\text { CLD (UPK, similar Bendix), } \\
\text { since 01/97 (add.): UV abs. TEI49C } \\
\text { since 01/97 (add.): KI (self built) } \\
\text { since 01/07 (add.): UV abs. TEI49i }\end{array}$ & $\begin{array}{l}\text { TEI } 49 \text { primary standard, } \\
\text { \#0423807729 } \\
\text { evaluation with Lambert } \\
\text { Beer law }\end{array}$ & $\begin{array}{l}1997 \text { and 2006: audits by WCC } \\
\mathrm{O}_{3} \text { : } \\
\text { http://www.empa.ch/plugin/ } \\
\text { template/empa/*/7571 } \\
\text { several informal } \\
\text { intercomparisons, e.g. with } \\
\text { DLR }(1999,2002,2004,2005)\end{array}$ & $0.6 \mathrm{ppb}$ or $1.2 \%$ \\
\hline & $\mathrm{CO}$ & $\begin{array}{l}\text { since 01/1995 NDIR (TE 48S \# } \\
\text { 50873-286) with modifications } \\
\text { following Parrish et al. (1994). } \\
\text { since 06/2004 (add): VUVR } \\
\text { (AL 5001 \# 142) }\end{array}$ & $\begin{array}{l}\text { since 11/07: NOAA/ESRL } \\
\text { standard gas \#CA07441 } \\
\text { before: several working } \\
\text { standards (range } 1 \text { to } 40 \mathrm{ppm} \text { ) } \\
\text { affiliated to GMD standard by } \\
\text { GAW-WCC audits }\end{array}$ & $\begin{array}{l}1997 \text { and 2006: audits by WCC } \\
\text { CO: } \\
\text { http://www.empa.ch/plugin/ } \\
\text { template/empa/*/7571 } \\
\text { several informal } \\
\text { intercomparisons, e.g. with } \\
\text { DLR (1999, 2002, 2004, 2005) } \\
\text { Gilge (2005) }\end{array}$ & $\begin{array}{l}\text { VUV: } 1.1 \mathrm{ppb} \text { or } 1.1 \% \\
\text { NDIR: } 7.9 \text { ppb or } 8 \%\end{array}$ \\
\hline & $\mathrm{NO}_{2}$ & $\begin{array}{l}\text { since 01/96: ECO Physics CLD } 770 \\
\mathrm{Al} \text { ppt \#77302 with PLC } 760 \text { (NO and } \\
\mathrm{NO}_{2} \text { ) } \\
\text { since 10/98 (add.): ECO Physics } \\
\text { CLD } 770 \mathrm{AL} \text { ppt } \# 77301 \text { with } \\
\text { self built } \mathrm{Au} \text {-converter (NO and } \mathrm{NO}_{\mathrm{y}} \text { ) } \\
\text { since } 08 / 05 \text { (add.): TEI } 42 \mathrm{C} \mathrm{TL} \\
\# 0521312373 \text { with Mo and BLC } \\
\text { converter }\left(\mathrm{NO}_{2} \text { and } \mathrm{NO}_{\mathrm{x}(\mathrm{Mo})}\right)\end{array}$ & $\begin{array}{l}\text { Since 10/08: NPL standard gas } \\
\text { (NO) \#195524SG } \\
\text { before: several working } \\
\text { standards (NO, range } 10 \text { and } \\
100 \text { ppm) confirmed by } \\
\text { intercomparisons } \\
\text { add. permeation tubes, } \\
\text { gas phase titration }\end{array}$ & $\begin{array}{l}\text { several informal } \\
\text { intercomparisons, e.g. with } \\
\text { DLR (1999, 2002) } \\
\text { Mannschreck et al. (2004) }\end{array}$ & 20 ppt or $3.6 \%$ \\
\hline \multirow[t]{3}{*}{ JFJ } & $\mathrm{O}_{3}$ & $\begin{array}{l}\text { UV-Abs. TEI 49C } \\
\text { backup: Environics S300 till 01/07; } \\
\text { since then: TEI 49C }\end{array}$ & Reference: NIST SRP\#15 & $\begin{array}{l}\text { Brönnimann et al. (2000) } \\
\text { Zanis et al. (2007), } 1999 \text { and } \\
\text { 2006: audits by } \mathrm{WCC} \mathrm{O}_{3} \text { : } \\
\text { http://www.empa.ch/plugin/ } \\
\text { template/empa/*/7571 }\end{array}$ & $1 \mathrm{hr}: 1.2 \mathrm{ppb}$ or $2 \%$ \\
\hline & $\mathrm{CO}$ & $\begin{array}{l}\text { NDIR } \\
\text { HORIBA APMA } 360 \text { (before 5.6.07) } \\
\text { HORIBA APMA } 370 \text { (since 5.6.07) }\end{array}$ & $\begin{array}{l}\text { NIST, NMI standard gases } \\
\text { 96-10/99: NIST SRM 1677c } \\
\text { 10/99-01/01: NMI PRM AC11 } \\
\text { 01/01-05/06: NIST SRM 1677c } \\
\text { 05/06-: NIST SRM 2612a. } \\
\text { compared and confirmed } \\
\text { with NOAA/ESRL cylinders } \\
\text { \#CA02859 and \#CA02854 }\end{array}$ & $\begin{array}{l}\text { Zellweger et al. ( } 2009 \text { ) } \\
1997 \text { and 2006: audits by WCC } \\
\mathrm{O}_{3} \text { : } \\
\text { http://www.empa.ch/plugin/ } \\
\text { template/empa/*/7571 }\end{array}$ & $1 \mathrm{hr}: 2.4 \mathrm{ppb}$ or $5 \%(1 \sigma)$ \\
\hline & $\mathrm{NO}_{2}$ & $\begin{array}{l}\text { CLD / PLC } \\
\text { CLD 770/PLC } 760 \text { (before 18.12.00) } \\
\text { CLD 770/PLC } 762 \text { (to 22.1.07) } \\
\text { CLD 89p/PLC } 762 \text { (since } 22.1 .07 \text { ) }\end{array}$ & $\begin{array}{l}\text { 1991-09/01: NIST SRM 2629a } \\
\text { Since 09/01: NMI PRM BD11 }\end{array}$ & Zellweger et al. (2003) & $\begin{array}{l}\mathrm{NO}_{2}: \\
\pm 10 \% \text { at } 500 \text { ppt }(1 \sigma)\end{array}$ \\
\hline \multirow[t]{2}{*}{ SNB } & $\mathrm{O}_{3}$ & $\begin{array}{l}\text { UV-Abs. } \\
\text { TE 49C }\end{array}$ & $\begin{array}{l}\text { TE 49C PS, traceable to NIST } \\
\text { SRP\#26 }\end{array}$ & audit by EMPA in August 1998 & $\begin{array}{l}1 \mathrm{~h}: \mathrm{U}=2\left(0.82^{2}+0.012^{2} \times^{2}\right)^{0.5} \\
\text { expanded uncertainty }(95 \%)\end{array}$ \\
\hline & $\mathrm{CO}$ & $\begin{array}{l}\text { NDIR: TE } 48 \text { with cryo trap } \\
\text { since 2002: HORIBA APMA } 360\end{array}$ & $\begin{array}{l}\text { Working standards, traceable to } \\
\text { VSL primary gas standards }\end{array}$ & audit by EMPA in august 1998 & expanded: $40 \mathrm{ppb}$ or $10 \%$ \\
\hline \multirow[t]{2}{*}{ ZUG / ZSF } & $\mathrm{O}_{3}$ & UV-Abs. TE 49C & $\begin{array}{l}\text { UBA laboratory, national } \\
\text { standard normal for Ozone, } \\
\text { adjusted to NIST }\end{array}$ & $\begin{array}{l}\text { 1996, } 2001 \text { and 2006: audits by } \\
\text { WCC O } \mathrm{O}_{3} \text { : } \\
\text { http://www.empa.ch/plugin/ } \\
\text { template/empa/*/7571 }\end{array}$ & $\begin{array}{l}0.7 \mathrm{ppb} \text { or } 1.3 \% \text { with } \\
(1-\alpha)=5 \%\end{array}$ \\
\hline & $\mathrm{CO}$ & $\begin{array}{l}\text { NDIR TE } 48 \text { CTL with cryo trap } \\
\text { since 10/2004 (add): VUVR } \\
(\text { AL 5001) }\end{array}$ & NOAA/CMDL & $\begin{array}{l}1996 \text { and 2001: audits by WCC } \\
\mathrm{O}_{3} \text { : } \\
\text { http://www.empa.ch/plugin/ } \\
\text { template/empa/*/7571 }\end{array}$ & $\begin{array}{l}1.8 \mathrm{ppb} \text { or } 1.8 \% \text { with } \\
(1-\alpha)=5 \%\end{array}$ \\
\hline
\end{tabular}

with the GC-FID technique after passing a heated catalyst (Zellweger et al., 2009) since February 2005. These time series are used for an independent quality control of the $\mathrm{CO}$ data based on the NDIR technique at least for the last couple of years. For the sake of data set homogeneity, only the NDIR data are used here for the evaluation of the $\mathrm{CO}$ time series. At ZSF, also a TE $48 \mathrm{~S}$ is used in combination with a cryo-trap for removing water vapour. At SNB in 2002 instrumentation for $\mathrm{CO}$ was changed from a TE 48 with cryo-trap to Horiba APMA360 which is used up to now. Replacing or in addition to NDIR, at HPB (since June 2004) and at ZSF (since October 2004) vacuum UV resonance fluorescence 
instruments (VUVR, Aero Laser, AL 5001) have been used. This instrument is specific to $\mathrm{CO}$ with only low water interference, which is excluded by use of a Nafion ${ }^{\mathrm{TM}}$ dryer. It has a better time resolution, sensitivity, and repeatability than the NDIR technique (Zellweger et al., 2009). CO calibrations are based on commercial standards in the ppm range or compressed air standards provided by the Central Calibration Laboratory for CO (CCL-CO, NOAA/GMD) (Table 2). Uncertainties depend on the used technique, the frequency of zero and span measurements, and specific instrument factors.

Nitrogen dioxide $\left(\mathrm{NO}_{2}\right)$ is measured after photolytic conversion to nitric oxide (NO) by chemiluminescence technique (CLD) using the reaction of $\mathrm{NO}$ with $\mathrm{O}_{3}$. Generally, instruments by ECOPHYSICS are used (CLD 770 or 89p, PLC 762 or 760), at Sonnblick the less sensitive TE 42C (Thermo Environment Inc.) and in addition the "EMEP" Sodium Iodide method with a time resolution of one day have been used. For $\mathrm{NO}_{2}$ the situation with respect to standardization and station audits is different compared to the other compounds as no GAW WCC or CCL exist and no audits could be performed so far. Thus, Table 2 lists comparisons with other institutions as a reference for an independent check of the data quality.

The uncertainties of the 1-h mean values are generally less than $1.2 \mathrm{ppb}$ or $2 \%$ for ozone, $50 \mathrm{ppt}$ or $10 \%$ for $\mathrm{NO}_{2}$, and $8 \mathrm{ppb}$ or $8 \%$ for CO by NDIR (JFJ: $2.4 \mathrm{ppb}$ and $5 \%$, the lower uncertainties for $\mathrm{CO}$ at JFJ are due to the use of crossflow modulation technique (Horiba) which at JFJ yielded lower zero-drift than measurements by the gas filter correlation technique) and $2 \mathrm{ppb}$ or $2 \%$ for CO by VUVR. In case of $\mathrm{NO}_{2}$ and $\mathrm{CO}$, the uncertainties comprise the systematic uncertainty of the calibration gas and the dilution process, which is generally at $3 \%$ for $\mathrm{NO}_{2}$ and $2 \%$ for $\mathrm{CO}$. All other statistical error contributions will cancel out in the mean error of the monthly mean values, which are then only determined by the systematic uncertainties. At all stations, calibrations are traceable to primary reference material by NMI's (National Metrology Institutes) for $\mathrm{NO}_{2}$, by NOAA-ESRL, the Central Calibration Laboratory for CO, or to NIST standard reference photometer SRP\#2 in case of ozone.

For periods without primary reference material available at the station, the standards used were cross checked in intercomparisons or by considerable overlap with other standards that could at other times be related to primary reference gases. Given the range of uncertainties, trend analysis of the long-time monitoring data are possible only within the range of these uncertainties.

\subsection{The consistency of station standards used for calibration for the period 1995-2007}

The history of station standards is shown in Table 2. For consistency long-term time series have to be traceable to the corresponding GAW scales hosted by the CCL's. Results of station audits as well as round robins are the prime measure to use. Here, "round robin" is used for test gas samples provided by the GAW Central Laboratories and circulated among GAW stations as a blind intercomparison. They provide information about data quality and comparability (Buchmann et al., 2009). For periods between audits or round robins, the traceability of station standards is documented in the following section. Finally the results of informal comparisons with other institutions are used as occasional checks.

This section goes through the three trace gases station by station.

\subsubsection{Hohenpeissenberg}

$\mathrm{O}_{3}$ was first audited by the WCC in November 1997. A deviation of 3.1\% between stations ozone reference (TE 49 PS) and WCC transfer standard was found. The reference instrument was adjusted and the data were corrected accordingly. Next audit took place in June 2006 with a deviation of $1 \%$. Taking into account the deviation between the transfer standard by WCC-Empa and the standard reference photometer of about $1 \%$, no significant deviation was found and no adjustment was made. Since all calibration checks during the measuring period taken into account here (1995-2007) generally gave deviations below $1 \%$ between ozone monitor (TE 49C) and stations standard (TE 49 PS), the station reference was stable within $1 \%$ for the whole period.

For CO, the calibration is related to a GMD standard gas purchased in 2007 and thus uses the GAW-CO scale WMO-2000. Since 2004 and ongoing, two types of working standards consisting of commercial mixtures in the $1 \mathrm{ppm}$ $(+/-5 \%$ stated uncertainty) and the $40 \mathrm{ppm}(+/-2 \%)$ range are used, with the $1 \mathrm{ppm}$ standard for the undiluted and regular calibration of the used monitors, and the $40 \mathrm{ppm}$ mixture to calibrate and check the stability of the $1 \mathrm{ppm}$ standard after dilution to some $150 \mathrm{ppb}$. Prior to 2004, only a $40 \mathrm{ppm}$ mixture with dilution was used to calibrate the NDIR system. Thus, prior to 2007 the $40 \mathrm{ppm}$ mixtures were used as station standards. The first of these station standards was compared during the CO audit by WCC in 1997 with resulting deviations of less than $1.3 \%$ which was better than the uncertainty of the NDIR instrument. New calibration gases always fitted to the respective older ones within the uncertainty of the instrument $(<2 \%$ for NDIR and $<1 \%$ for VUVR, respectively). Since 2007, a NOAA/GMD standard gas serves as stations standard. Deviations of round robins with GMD test gases in 2005 and 2009 and an audit by WCC in 2006 were on average smaller than 1\%. Since April 2006 the HPB data are compared to the $\mathrm{CO}$ concentrations derived from the NOAA/GMD flask sampling at HPB. On average (2006-2008) deviations are smaller than $1.5 \%$. In summary, the used CO scale at HPB has been stable within the range of uncertainty of $2 \%$ during the period of investigation (19952007). 
Since 1995 six different NO standards (Table 2) were used at HPB. New calibration gases always fit to the respective older ones within the uncertainty of the instrument and dilution process $(<2 \%)$. Informal comparisons with DLR (German Aerospace Centre) in the years 1999 and 2002 resulted in deviations of less than 2\%. Since January 2009 a NPL calibration gas serves as stations standard. Deviation to the former standard is $<1 \%$. The NO standards are used for $\mathrm{NO}$ and $\mathrm{NO}_{2}$ calibration. The $\mathrm{NO}_{2}$ to $\mathrm{NO}$ converter efficiency is determined by use of $\mathrm{NO}_{2}$ calibration gas obtained by gasphase-titration of the NO standard gas with ozone.

\subsubsection{Jungfraujoch}

JFJ was audited by the WCC for $\mathrm{O}_{3}$ and $\mathrm{CO}$ in January 1999 and in July 2006 (http://www.empa.ch/plugin/template/ empa/*/7571). For $\mathrm{O}_{3}$, an offset of $0.1 \mathrm{ppb}$ and a relative deviation of $0.4 \%$ and a negative offset of $0.16 \mathrm{ppb}$ and a relative deviation of $0.5 \%$ were determined for the range of 0 $100 \mathrm{ppb}$ and 0-90 ppb in 1999 and 2006, respectively. Both audits assessed the $\mathrm{O}_{3}$ data quality as good. The audit for $\mathrm{CO}$ in 1999 revealed a deviation of 1 to $3 \%$ that is clearly within the measurement uncertainty. Thus, the applied CO setup was assessed as very good. A similar result, i.e. an agreement well within the measurement uncertainty, was achieved in 2006. The 2006 audit was followed by a two months field study at JFJ comparing the three continuously operating $\mathrm{CO}$ analyzers (NDIR, GC-HgO and GC-FID and the WCC reference instrument (UV resonance fluorescence instrument, Aero Laser, AL 5001). The intercomparison exhibited an agreement among all techniques better than $2 \%$ for hourly averages and confirmed that the NDIR technique provides reliable data when considering hourly or higher aggregates; thus the NDIR technique is well suited for long-term monitoring even at remote sites (Zellweger et al., 2009).

The $\mathrm{O}_{3}$ analyzer is calibrated on site every three months with a TEI 49-PS reference instrument (traceable to NIST SRP\#15). The procedure follows a multipoint calibration at approximately $30,60,90,120 \mathrm{ppb} \mathrm{O}_{3}$ and a zero point and an $\mathrm{O}_{3}$ scrubber test at $400 \mathrm{ppb}$. The analyzer is corrected accordingly if the offset varies $>0.5 \mathrm{ppb}$ and/or the slope deviates $>0.5 \%$. The estimated measurement uncertainty for hourly averages is $1.2 \mathrm{ppb}$ and $2 \%$ for values below and above $60 \mathrm{ppb}$, respectively.

Automatic zero checks of the $\mathrm{CO}$ analyzer are performed every $49 \mathrm{~h}$. In addition, calibrations are done manually during station maintenance (every 2 to 3 weeks). Due to the linearity of the instrument, undiluted calibration gases in the low ppm range are favored over diluted samples close to ambient concentrations since the latter features larger uncertainties. The detection limit (zero $\pm 3 \sigma$ of the zero signal) is about $30 \mathrm{ppb}$. The overall measurement uncertainty for a 10 min mean value is estimated to be $<10 \%$ below $100 \mathrm{ppb}$ and $<5 \%$ above $100 \mathrm{ppb}$.
The NO analyzers are automatically calibrated every 23 (CLD 770) to 37 (CLD 89 p) hours. Zero air and NO standard gas ( $\sim 5 \mathrm{ppm} \mathrm{NO}$ in $\mathrm{N}_{2}$, diluted with zero air to approximately $48 \mathrm{ppb}$ ) is applied during calibration. The conversion efficiency of the converter is determined by gas phase titration of NO with ozone in the same interval. The conversion efficiency of the PLC usually ranged from 60 to $35 \%$. Lamps (xenon arc lamps for PLC760, metal halide lamps for PLC762) were replaced when reaching lower efficiencies. Overall uncertainties for hourly averages are estimated to be $\pm 5 \%$ for $\mathrm{NO}$ and $\pm 10 \%$ for $\mathrm{NO}_{2}$ at ambient levels of $500 \mathrm{ppt}$ (1 sigma) (Zellweger et al, 2000). They include the precision of the CLD, the NO standard uncertainty, and the conversion efficiencies of the PLC.

On site calibration standards for $\mathrm{CO}$ and $\mathrm{NO}_{2}$ are calibrated at Empa before use and before extinction against the reference standards listed in Table 2. All instruments undergo comprehensive instrument tests and quality check after first receipt and before being installed at JFJ. In operation, instruments are replaced in regular intervalls (TEI 49C every 2 years; Horiba APMA yearly) and sent to manufacturer representatives in Switzerland for service such as cleaning and replacement of wear parts. This is again followed by standard quality checks/instrument tests at Empa. $\mathrm{NO}_{2}$ instruments are serviced yearly on-site by an ECOPHYSICS service engineer. Standard operating procedures exist for the instrument tests, the regular on-site maintenance and daily and monthly data processing procedures.

\subsubsection{Hoher Sonnblick}

SNB was audited by WCC for $\mathrm{O}_{3}$ and CO (EMPA) in August 1998. The results for $\mathrm{O}_{3}$ and $\mathrm{CO}$ were rated as good, however with high uncertainties for low $\mathrm{CO}$ concentrations due to the monitoring technique. Therefore a change of the monitor was proposed. The report was published as EMPA-WCC Report 98/4 (http://www.empa.ch/plugin/ template/empa/*/7571).

$\mathrm{O}_{3}$ calibrations are traceable to the standards of the calibration laboratory at the Environment Agency Austria (EAA) in Vienna (accredited according to EN ISO/IEC 17025), which is the Austrian Reference Laboratory for Air Quality according to the EC Directives. Therefore the $\mathrm{O}_{3}$ measurements are traceable to the Austrian national Etalon for $\mathrm{O}_{3}$, the NIST SRP \#26 (primary reference photometer). As transfer standard a TE 49C PS is used.

$\mathrm{CO}$ measurements are traceable to primary reference gas mixtures from VSL, the Dutch metrological institute. The concentrated primary reference gas mixture is diluted by dynamic dilution to concentrations in the measuring range.

Every year since 1998 a bilateral comparison of calibration standards for $\mathrm{CO}$ and $\mathrm{O}_{3}$ with GAW-WCC (EMPA, CH) is performed. At EMPA the SNB CO standard has been testet against NIST, NPL and VSL standard gases which 
themselves were compared to NOAA \#CA02854 (WMO 2000 scale). The deviations have been always smaller than $1.5 \%$.

\subsubsection{Zugspitze/Schneefernerhaus}

The station was audited in 1996, 2001 and 2006 by WCC for $\mathrm{O}_{3}$. In 1996 the station instrument TE49C fulfils the assessment criteria as "good" for ozone concentrations higher than $20 \mathrm{ppb}$. For the concentration range relevant for the Zugspitze site, the deviations were very low, at only about $1 \%$. Therefore the data were not corrected. In 2001 and 2006 the TEI 49C field instrument clearly fulfilled the assessment criteria as "good" over the tested range up to $100 \mathrm{ppb}$. For details, please refer to: http://www.empa.ch/plugin/template/ empa/*/7571.

Homogeneity of the Zugspitze ozone time series: As ozone background concentrations increase with altitude, the move of the GAW site from Zugspitze summit to Schneefernerhaus some $300 \mathrm{~m}$ lower caused an inhomogeneity in the ozone time series and had to be compensated for. From 1978 until March 2002 ozone measurements were continuously taken at Zugspitze summit. Since April 2000 ozone measurements have been performed at the Schneefernerhaus site (ZSF). Measurements at Schneefernerhaus were systematically lower by $0.82 \mathrm{ppb}$, with a standard deviation of $0.99 \mathrm{ppb}$ for the monthly mean values during the period March 2002 October 2007. In order to account also for a constant deviation of the ZSF ozone calibrator in comparison to WCC's transfer standard, which amounted to $-0.65 \mathrm{ppb}$, a total correction of $+1.5 \mathrm{ppb}$ was added to Schneefernerhaus data for the time from April 2002 until October 2007.

From 1995 to March 2002 the GAW carbon monoxide measurements were performed at Zugspitze summit laboratory and at Schneefernerhaus thereafter. From 1995 up to March 2002 the CO concentrations were measured with a NDIR instrument TE48S.

In the 2001 audit, due to instrumental problems during the audit, the mean deviation was $17.7 \%$ below the reference. About half of the deviation can be explained by the revision of the CO scale which had been applied to the transfer standard before the audit and which had not been communicated to the audited station before. Based on these circumstances no correction was made for $\mathrm{CO}$ time series data in the corresponding time range. A thorough evaluation of the effects of a principally possible correction given by this audit showed that the negative trend would have become even stronger. For this evaluation only Zugspitze CO summit data had been used.

\subsection{Data}

Data of all four stations are available as $1 \mathrm{~h}$ average values at http://gaw.kishou.go.jp/wdegg/. Generally, 2/3 data coverage criteria were used, i.e. more than $2 / 3$ of the data are

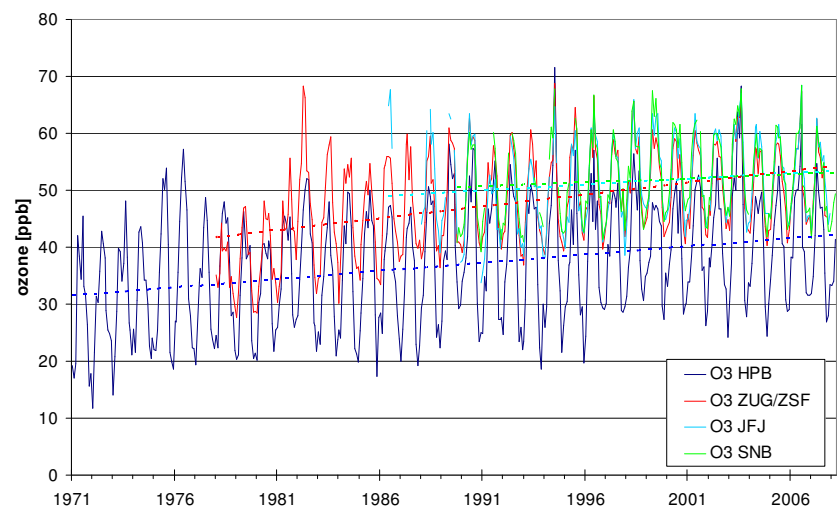

Fig. 1. $\mathrm{O}_{3}$ time series at the respective "DACH"-sites: blue: HPB; red: ZUG/ZSF, light blue: JFJ, green: SNB. Monthly mean mixing ratios (solid) and linear trend (dashed)

required to give a 1-h value. Monthly mean values have been calculated from these $1-\mathrm{h}$ data, if more than $2 / 3$ of the $1-\mathrm{h}$ data were available.

The statistical significance of a trend is determined based on linear regression and t-test $\hat{t}=|r| \cdot \sqrt{\frac{n-2}{1-r^{2}}}$, (two-sided test, with $r$ : Pearson correlation coefficient, and $n$ : number of data points). We decided to use this rather simple statistics basically because there remain some hard to quantify uncertainties with respect to the homogeneity of the time series, e.g. instrument and calibration gas changes (see uncertainties above), and for the fact that the available time series of up to 13 years are rather short. Thus, we felt that the use of statistics for qualifying the significance of the small trends found in this paper still needs to be interpreted with care. Consequently, we stayed with very simple statistics. If the probability of the null-hypothesis (the trend is zero) is smaller than $5 \%$, we use the term "statistically significant", at $<1 \%$ we use "highly statistically significant".

\section{Results}

\subsection{Ozone}

The time series of ozone of the four DACH stations are compiled in Fig. 1 based on monthly mean data. The longest uninterrupted time series has been measured at Hohenpeissenberg (HPB) since 1971. Zugspitze (ZUG) started in 1975 with a change in site in 2001 (ZSF), Jungfraujoch (JFJ) in 1986 (with some gaps in the beginning), and Sonnblick (SNB) measures since 1989. At all sites, a significant linear increase over the respective measurement intervals is observed, with linear trends and $95 \%$ confidence intervals of $0.31 \pm 0.09 \mathrm{ppb} / \mathrm{y}$ (HPB), $0.42 \pm 0.09 \mathrm{ppb} / \mathrm{y}$ (ZUG/ZSF), $0.26 \pm 0.16 \mathrm{ppb} / \mathrm{y}(\mathrm{JFJ})$, and $0.22 \pm 0.17 \mathrm{ppb} / \mathrm{y}(\mathrm{SNB})$, respectively. 


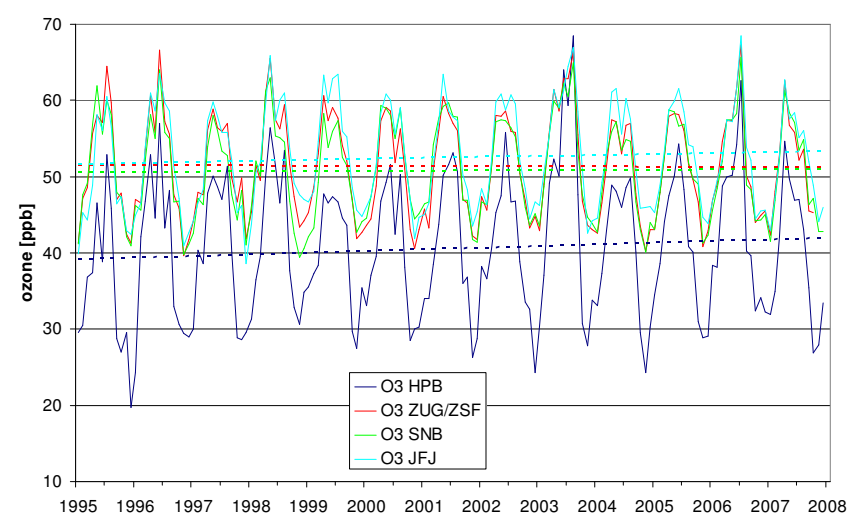

Fig. 2. $\mathrm{O}_{3}$ time series at the respective "DACH" sites since 1995; blue: HPB; red: ZUG/ZSF, light blue: JFJ, green: SNB. Monthly mean mixing ratios (solid) and linear trend (dashed).

In order to be able to compare trends of the respective time series, a reference period of 1995-2007 will be considered throughout this paper. This period was chosen with respect to the other trace gases time series, which generally did not start before 1995 . Obviously, the ozone time series at the high alpine stations are tracking each other very closely. Increasing values though still observed in the beginning at some stations, e.g. HPB and JFJ, have levelled off in the last years (Fig. 2) and trends are nonsignificant in this period. For the period before 1995, positive trends have been calculated: $0.38 \pm 0.17 \mathrm{ppb} / \mathrm{y}$ for HPB (1971-1994), $0.68 \pm 0.22 \mathrm{ppb} / \mathrm{y}$ for ZUG (1975-1994), and $0.64 \pm 1.10 \mathrm{ppb} / \mathrm{y}$ for SBO (1989-1994). Only at JFJ, due to high mixing ratios in the first years of measurement, a negative trend of $-0.67 \pm 0.83 \mathrm{ppb} / \mathrm{y}$ (1986-1994) was observed (uncertainties representing the $95 \%$ confidence level).

Due to the different altitudes of the stations, vertical gradients (see also Chevalier et al., 2007) and different annual cycles (Fig. 3) are observed. HPB has on average lower mixing ratios and a more pronounced seasonal variation since HPB is more frequently in the planetary boundary layer compared to the other stations. Accordingly, the annual cycle at HPB is more influenced by deposition to the ground and titration due the reactions with $\mathrm{NO}$ and, in summer time, photochemical ozone production from elevated precursor concentrations in the boundary layer. All stations show typical continental annual cycles with a broad spring/summer maximum and indications for more pronounced spring maxima for the highest sites JFJ and SNB. This differs from remote sites where a spring maximum in April/May is observed (Gomiscek et al., 1999; Monks, 2000). The broad spring/summer maximum is thus considered to be due to a combination of background impact and photochemical production from regional emissions in summer (Chevalier et al., 2007; Ribas and Penuelas, 2004).

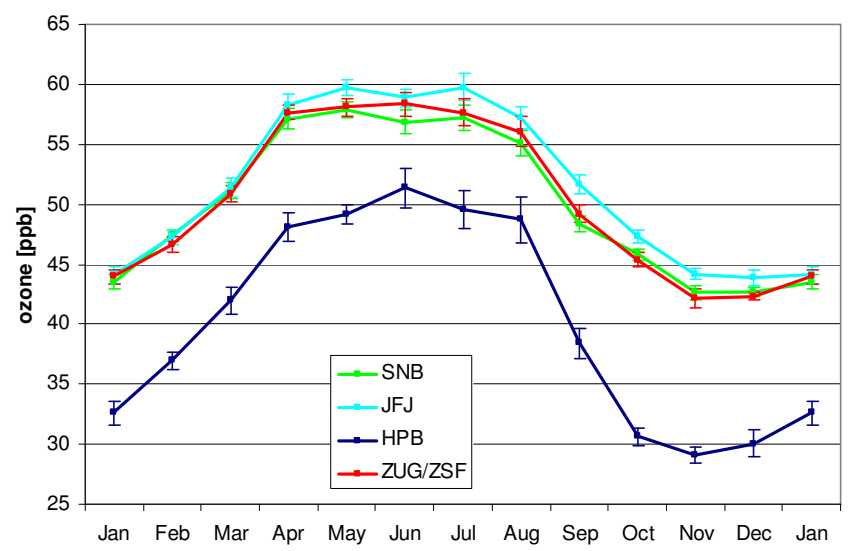

Fig. 3. $\mathrm{O}_{3}$ mean annual variation (1995-2007) at the respective "DACH" sites; blue: HPB; red: ZUG/ZSF, light blue: JFJ, green: SNB.

Time series of the percentile distributions (Fig. 4) with linear trends show effects as found in UK for rural sites (Jenkins, 2008): the lower percentiles increase over time and for most stations the maxima (HPB, SNB) and the upper percentiles (ZSF) decline. Only JFJ station shows consistent increases over all percentile classes. However, none of the percentile series shows a significant trend.

Figure 5 shows the seasonally separated trends for the four stations (spring: Mar, Apr, May; summer: Jun, Jul, Aug; autumn: Sep, Oct, Nov; winter: Dec, Jan, Feb). The three high alpine stations are very similar in levels and trends. For the individual stations, spring and summer values are comparable as well as autumn and winter values. However, positive trends are seen in winter and spring, and no trends or declining levels (ZSF, SNB) in summer and autumn. At HPB, positive trends are seen in all seasons, however, more pronounced in winter and spring. Generally, trends are mostly non-significant, just the positive trends at HPB and JFJ in winter are significant at a $95 \%$ confidence level.

Weekly cycles show clear signals of enhanced levels on working days compared to Sundays in summer, vice versa in autumn and winter, and in between in spring (Fig. 6). This points towards anthropogenic emission impacts even at the high elevated sites and in winter time when the stable atmosphere tends to suppress vertical exchange. Accordingly, the amplitude of the weekly cycles is weakest at the highest alpine sites (SNB, JFJ) with typically $1 \mathrm{ppb}$ compared to about $2 \mathrm{ppb}$ at HPB. In summer, maxima are generally on Wednesday or Thursday, minima on Sunday or Monday. In winter and autumn, maxima are typically on Saturday or Sunday, minima on Wednesday or Thursday. 

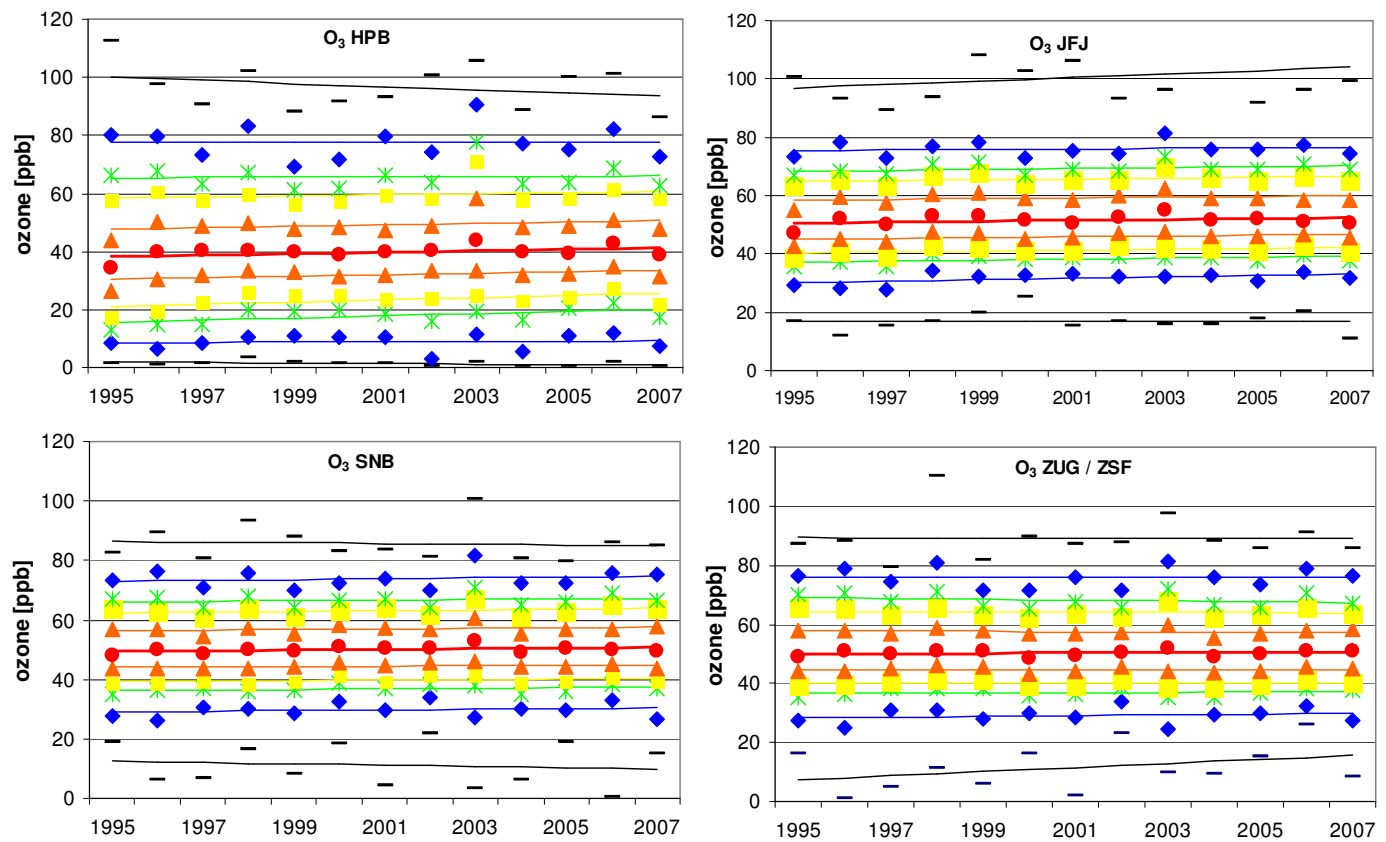

Fig. 4. $\mathrm{O}_{3}$ time series of annual percentiles and respective linear trends at the "DACH" sites since 1995; black: minimum and maximum, blue: 1- /99- ; green: 5- /95- , yellow: 10- /90- ; orange: 25- /75-percentiles, red: median.
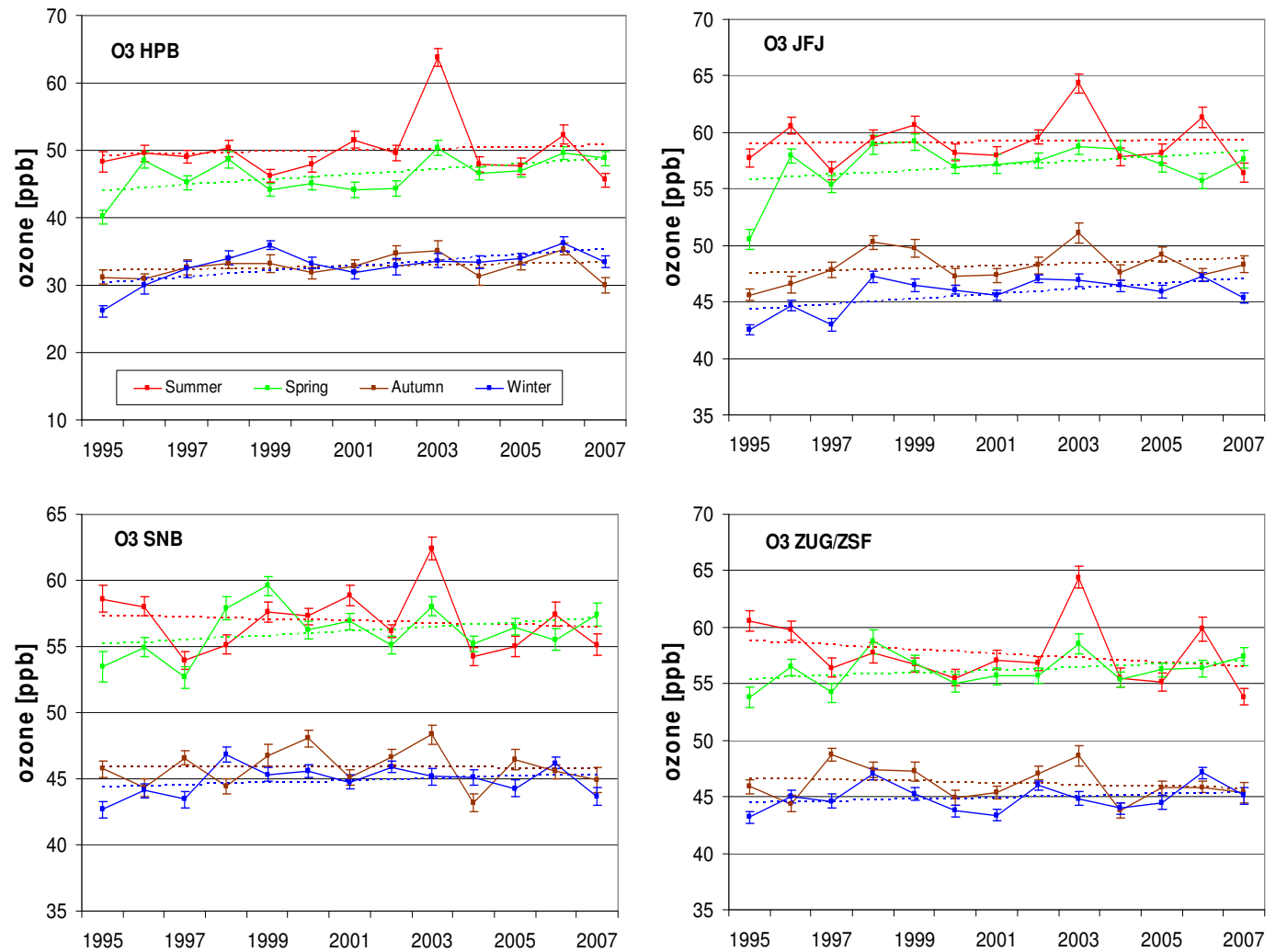

Fig. 5. $\mathrm{O}_{3}$ time series since 1995 for the different seasons at the respective "DACH" sites; blue: winter; green: spring; red: summer, brown: autumn yearly mean mixing ratios with standard error of the mean (solid) and linear trend (dashed). 

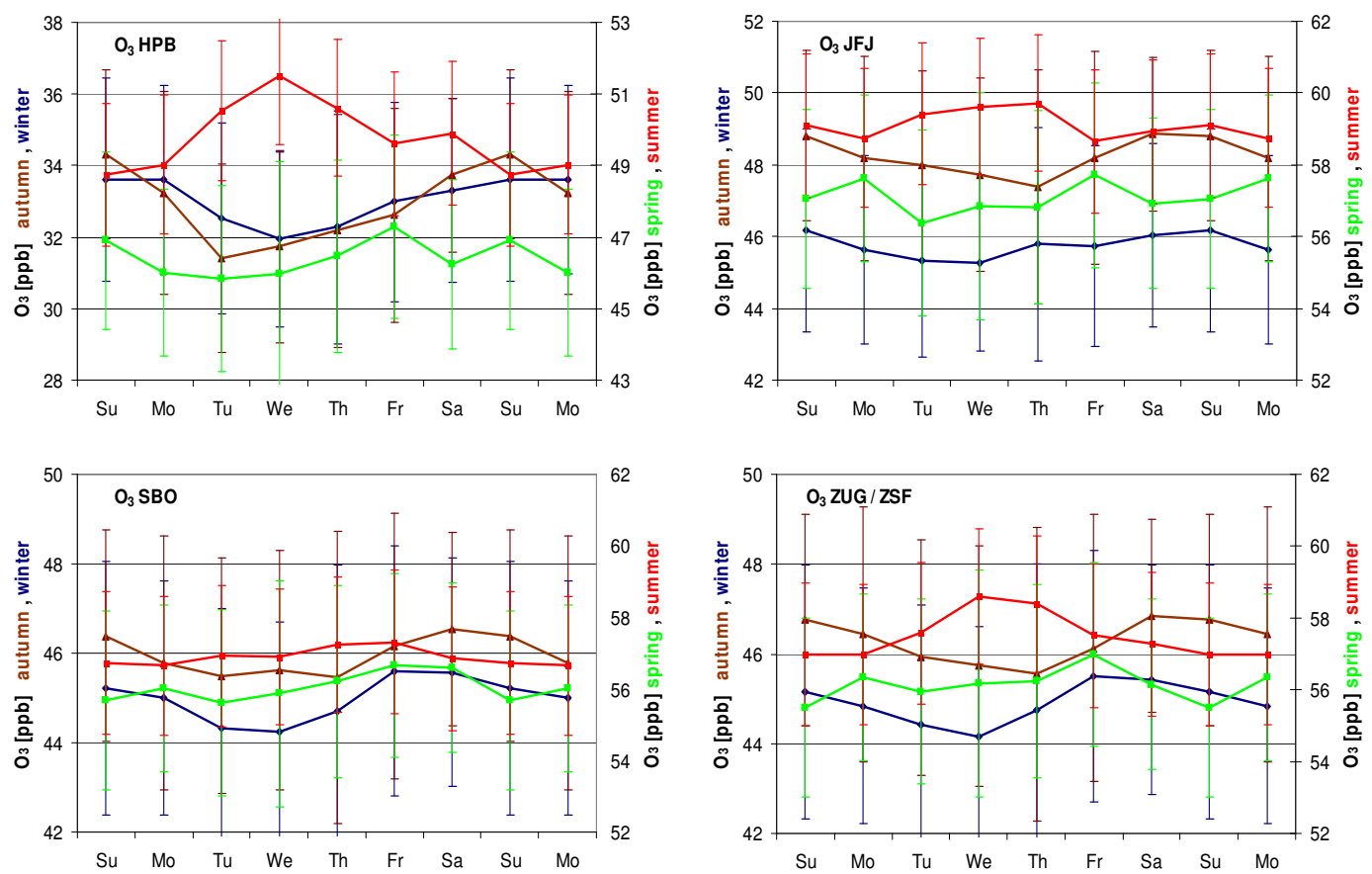

Fig. 6. Weekly variation of $\mathrm{O}_{3}$ for the different seasons at the respective "DACH" sites; blue: winter, brown: autumn (left axis), red: summer, green: spring (right axis). The errors bars indicate the standard error of the mean.

\subsection{Carbon monoxide}

The time series of the monthly mean CO (carbon monoxide) are shown in Fig. 7 for the various DACH sites. Periods of available data are quite different and only HPB (19952007) and JFJ (1996-2007) have continuous long time series. Accordingly, trends of the shorter data sets of SNB (2002-2007) and ZUG (1995-2002) are mentioned here but will not be further discussed. Also, there appears to be an unresolved bias in the SNB data as they are substantially higher than from other high alpine stations and more comparable to the lowest site HPB. CO data of SNB are currently being re-evaluated and we won't discuss the absolute values but concentrate on relative results. Levels at the high elevated sites are generally lower than at HPB except for SNB. Mixing ratios are generally lower or similar at ZUG compared to JFJ, except for some episodes in 1997 with lower levels at JFJ. All stations show declining concentrations. Calculated trend and 95\% confidence interval for $\mathrm{JFJ}$ yield $-3.36 \pm 1.08 \mathrm{ppb} / \mathrm{y}$, which is a little larger than the trend calculated for quasi the same period for the filtered data for background conditions $-2.65 \pm 0.04 \mathrm{ppb} / \mathrm{y}$; Zellweger et al., 2009) and $-1.51 \pm 1.64 \mathrm{ppb} / \mathrm{y}$ for HPB. The shorter time series of ZUG yields $-3.16 \pm 1.08 \mathrm{ppb} / \mathrm{y}$; all three trends are significant at the $95 \%$ confidence level.

Clear annual cycles for all $\mathrm{CO}$ data sets are discerned (Fig. 8) as also reported in previous studies (e.g. Novelli, 2003). They are most pronounced at the lowest station, HPB, with seasonal amplitude of about $80 \mathrm{ppb}$ compared to $50 \mathrm{ppb}$

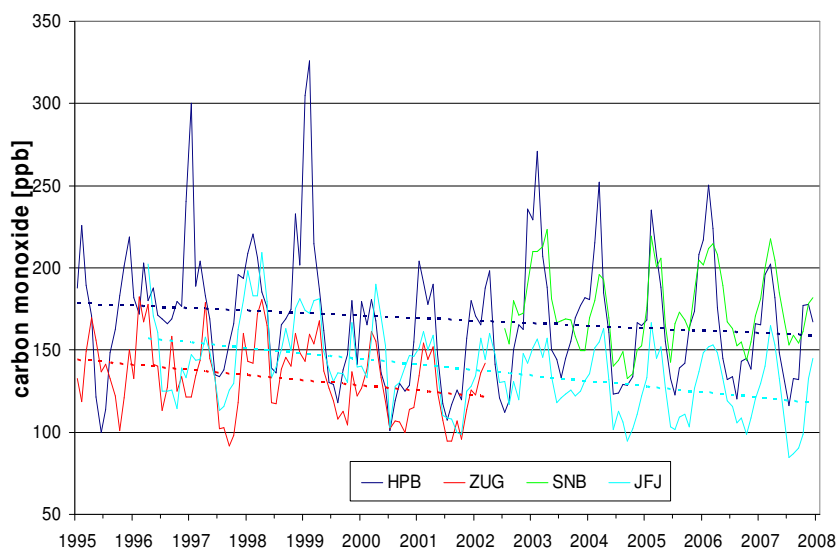

Fig. 7. CO time series since 1995 at the respective "DACH" sites; blue: HPB; red: ZUG, light blue: JFJ, green: SNB. Monthly mean mixing ratios (solid) and linear trend (dashed); SNB without linear trend (see text).

for the high elevates sites. The three high alpine sites show a continuous increase during winter towards a maximum in April, compared to a maximum in February at HPB. Minima in all data sets are generally in July; however, the higher sites exhibit a secondary minimum in October, most pronounced at ZUG. From April to July, the mixing ratios at all altitudes (JFJ, ZUG, HPB) are very similar with less than 15 ppb difference on average, indicating well mixed conditions. 


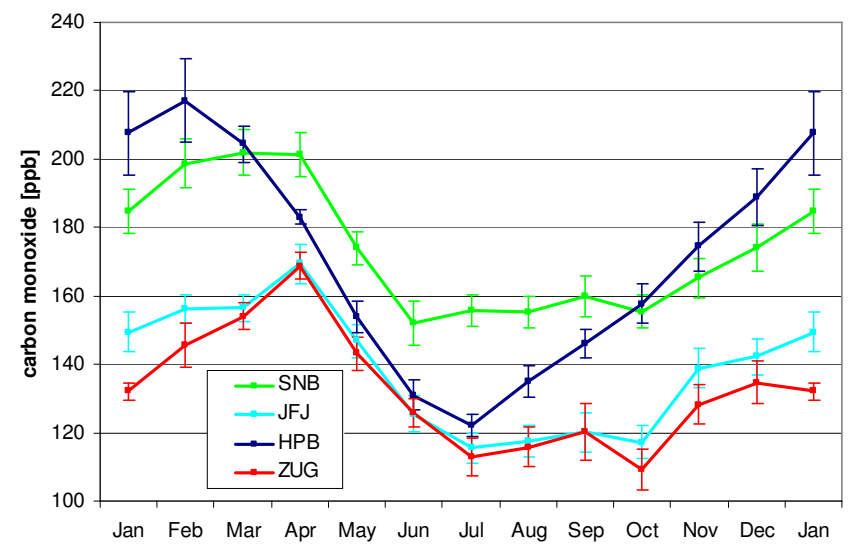

Fig. 8. CO mean annual variation at the "DACH"-sites, blue: HPB; red: ZUG, light blue: JFJ, green: SNB. Error bars indicate the standard error of the mean.

Trends in $\mathrm{CO}$ percentile distributions are generally more pronounced than for $\mathrm{O}_{3}$ (Fig. 9). At the highest site (JFJ), all percentiles exhibit downward trends, all significant except minima and maxima. At HPB, the picture is different with decreasing higher percentiles but increasing lower percentiles and no trend for the median. Here, only the 75-percentile downward trend and the upward trend of the minima are significant. The latter, however, was determined without considering the first 2 years which, due to an insufficient correction for water interference (NDIR instrument), especially at low CO concentration, show an enhanced scatter in the data which might have falsified the lowest measured values. The shorter time series of ZUG shows declines in the higher percentiles similar to JFJ (significant for 90- and 95percentile) but unchanged medians and lower percentiles.

The seasonal trends show for the sites SNB and JFJ mostly similar values in winter and spring, respectively in summer and autumn (Fig. 10). Winter spring differences are discernable at ZUG but appear to decline over time. At the low site HPB, the winter-spring difference up to the year 2000 is very large and declines afterwards, too. The spring trend at HPB is the only of the long time series with (non-significant) increasing mixing ratios, whereas all other seasonal trends (JFJ significant, HPB non-significant) are negative. Trends are very similar at JFJ for the four seasons. Before 2001, time series show higher values with more scatter, many of the series show rather low mixing ratios in 2000 or 2001 and reduced trends thereafter. The elevated mixing ratios in 1998 are a common feature at the high alpine sites - most likely caused by intense global biomass burning (e.g. Simmonds et al, 2005) -, whereas at HPB in 1998 only the autumn values are enhanced.

For carbon monoxide the weekly cycles do not show systematic differences between working days and weekends.

\subsection{Nitrogen dioxide}

Due to its shorter life-time of only a few hours in summer and 1-2 days in winter, $\mathrm{NO}_{2}$ is a good indicator for regional anthropogenic impact. Long time series of monthly mean mixing ratios are only available for JFJ (1995-2007) and HPB (mid of 1996-2007), data from 1995 from SNB are not presented here and from Zugspitze, though measurements have been performed, data are not available. The time series of $\mathrm{NO}_{2}$ show approximately 10 times lower values for JFJ compared to HPB. Both exhibit declining mixing ratios with very similar trends $(-0.014 \pm 0.008 \mathrm{ppb} / \mathrm{y}$ at JFJ and $-0.011 \pm 0.051 \mathrm{ppb} / \mathrm{y}$ at $\mathrm{HPB}$ ) which are highly significant at JFJ but non-significant at HPB at the 95\% confidence level. However, the decline at JFJ is largely determined by the high values of the first 2 years. The annual cycle (Fig. 12) at JFJ with seasonal changes of $0.1-0.2 \mathrm{ppb}$ is much less pronounced than at HPB with summer minima of $1.3 \mathrm{ppb}$ and winter maxima of $3.5 \mathrm{ppb}$, on average.

All $\mathrm{NO}_{2}$ percentile distributions (Fig. 13, log scale) at JFJ show a consistent downward trend, significant only for the 75- to 95-percentiles. In contrast, a mixed picture exists at HPB with declining mixing ratios in the 25- to 95percentile range (significant for 50- to 95-percentile), and slight increases for the lower and highest percentile classes (non-significant).

Seasonally separated, clear downward trends at JFJ are observable for all seasons (Fig. 14), significant in summer $(-0.021 \pm 0.017 \mathrm{ppb} / \mathrm{a})$ and autumn $(-0.033 \pm 0.019 \mathrm{ppb} / \mathrm{a})$. However, trends are largely due to the high mixing ratios of the first two years, 1995 and 1996, which might be potentially biased due to local construction activitites (Forrer et al., 2000). Thereafter, trends are much weaker and nonsignificant. At HPB, measurements started in mid 1996 and weak downward trends are consistently seen in all seasons. Weekly cycles clearly show up in all seasons at HPB and JFJ (Fig. 15). In contrast to ozone, the primarily emitted $\mathrm{NO}_{2}$ shows maximum mixing ratios always on working days and minima on Sundays. If the 1995-1996 JFJ data are not considered the weekly pattern is unchanged, however, at a lower level.

\subsection{Results for different sectors of wind direction}

Figure 16 displays the angular distribution of mixing ratios for the respective stations and trace gases averaged over intervals of $10^{\circ}$ (black). Also shown are the distributions of the vector-averaged wind directions (blue). In order to identify the contribution of different wind sectors to the trace gas average mixing ratios, the relative angular distributions of the respective trace gases weighted by the wind direction distribution are displayed as red curves. These were calculated by first multiplying the respective mean mixing ratio and the wind frequency in a given $10^{\circ}$ sector, and then normalizing these numbers by the corresponding integral over all wind 

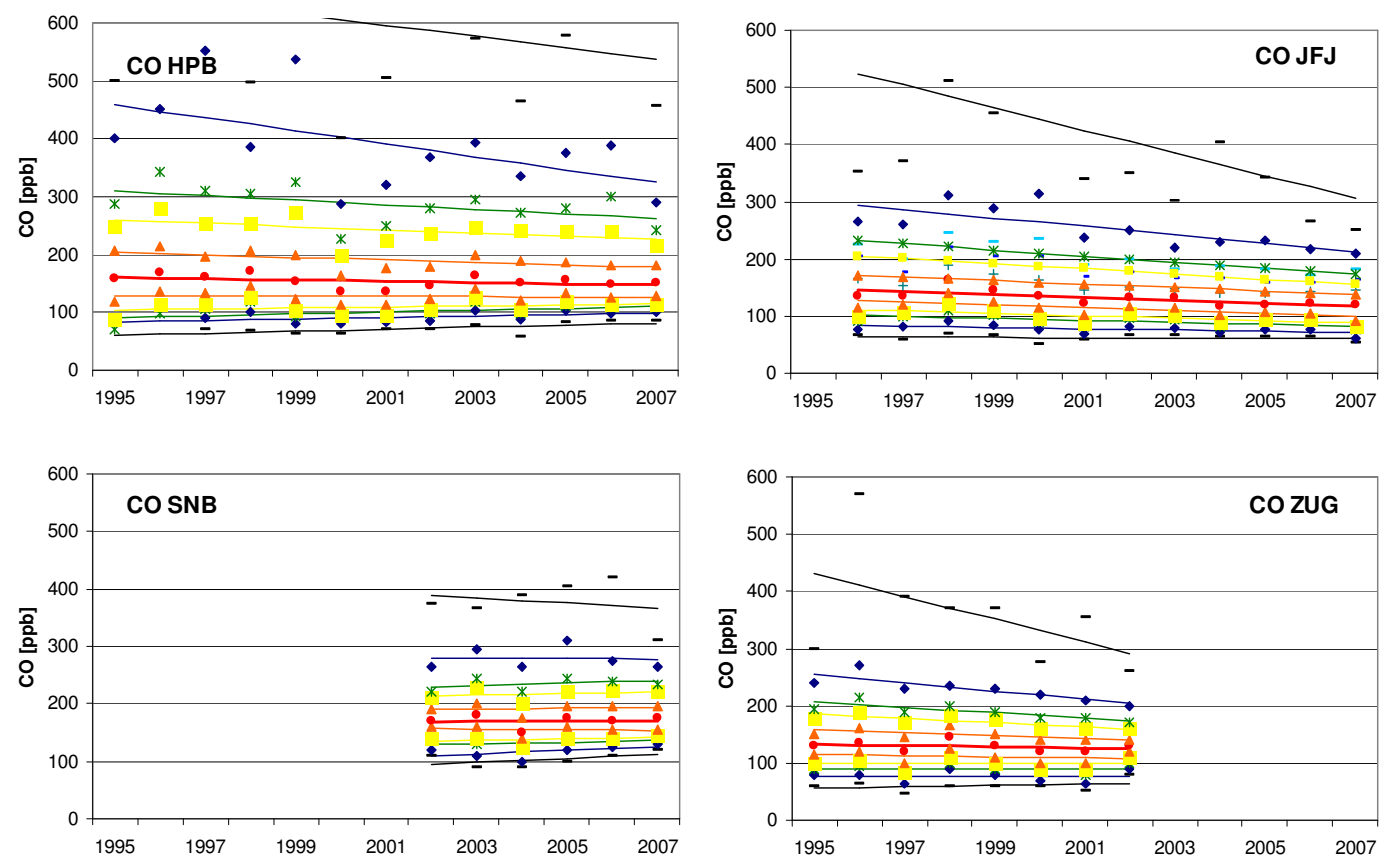

Fig. 9. CO time series of annual percentiles and respective linear trends at the "DACH" sites. since 1995; black: minimum and maximum, blue: 1- /99- ; green: 5- /95- , yellow: 10- /90- ; orange: 25- /75-percentiles, red: median.
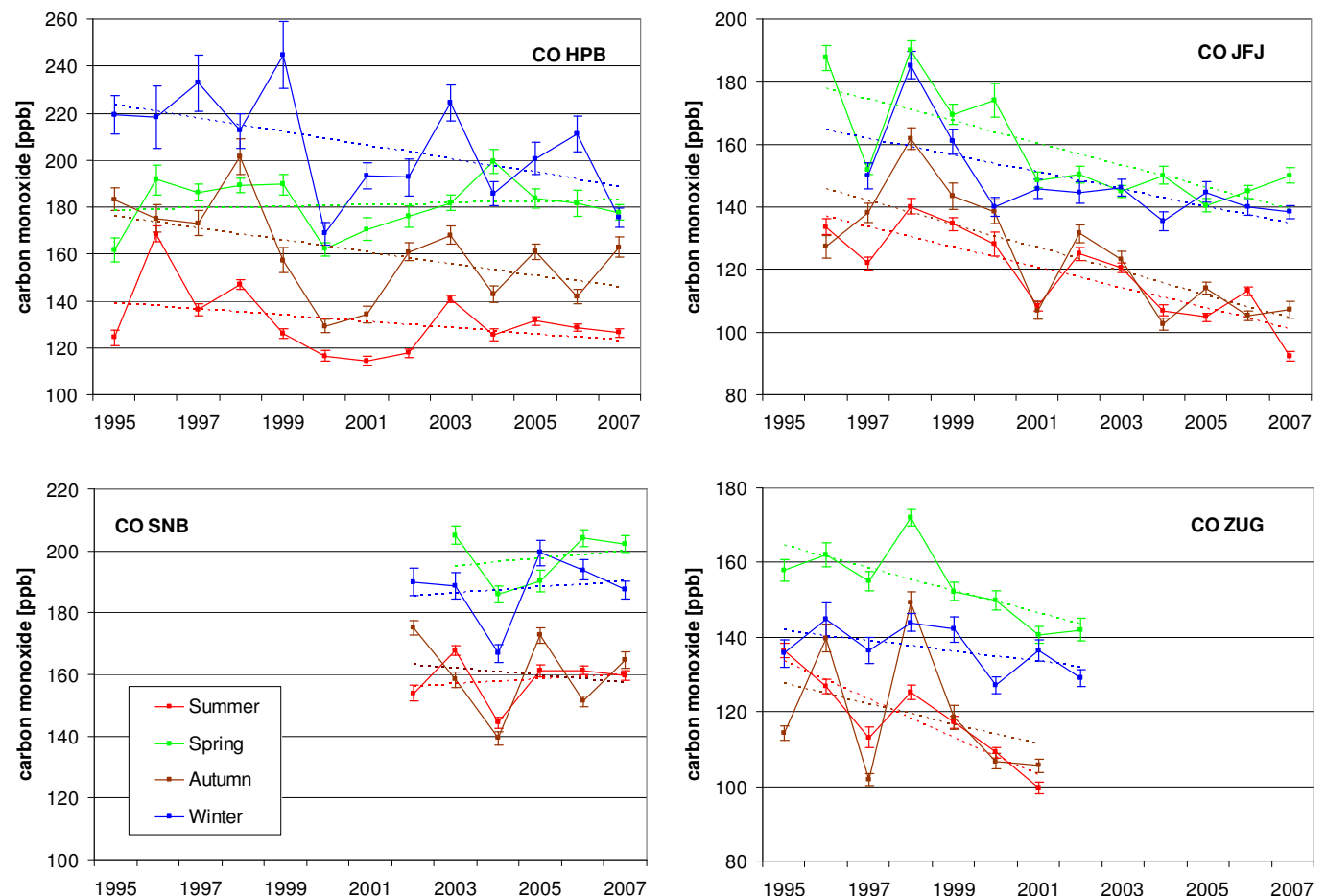

Fig. 10. CO time series since 1995 for the different seasons at the respective "DACH" sites; blue: winter; red: summer, brown: autumn, green: spring, yearly mean mixing ratios (solid) with standard error of the mean and linear trend (dashed). 


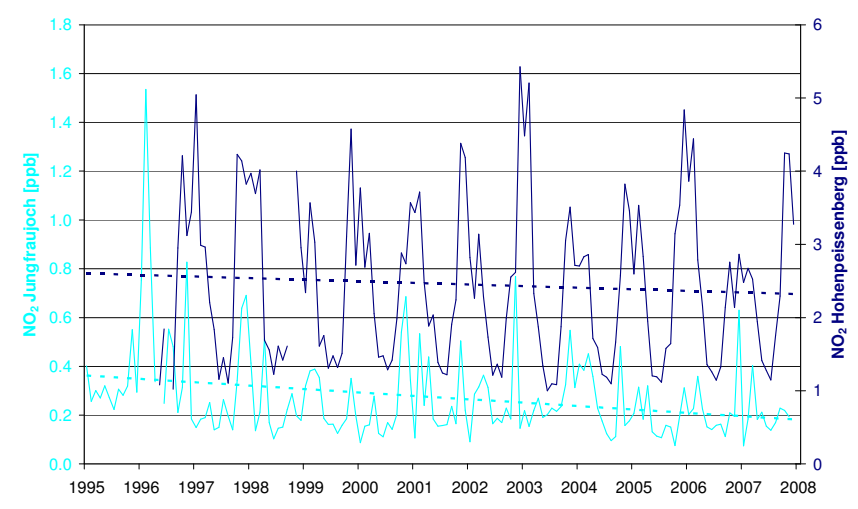

Fig. 11. $\mathrm{NO}_{2}$ time series since 1995 at the respective "DACH" sites, dark blue: HPB (right axis); light blue: JFJ (left axis). Monthly mean mixing ratios (solid) and linear trend (dashed).

sectors. All DACH sites show two major wind sectors which are partly influenced by the local topography, e.g. JFJ at the saddle between Moench and Jungfrau. Since there is only negligible dependence of ozone from the wind sector at SNB and ZUG/ZSF no figure is presented here.

For ozone at the high alpine stations, the least variation with wind direction is observed. The wind-distribution weighted curves are mostly identical to the distributions of the wind directions themselves, in the main wind sectors. At HPB (Fig. 16), the angular distribution varies between maxima in the SE and $\mathrm{N}$ sector of $45 \mathrm{ppb}$ and minima of $40 \mathrm{ppb}$ in the main wind sectors WSW and NE. Accordingly, the wind direction weighted distribution again does not indicate prevalence for either of the main wind sectors. CO shows more pronounced dependencies on wind directions (Fig. 16), and here differences in the main wind sectors can be clearly discerned: At HPB, higher concentrations are advected from the NE sector (on average $200 \mathrm{ppb}$ ) than from the WSW sector (170 ppb). Also, JFJ is exposed to higher mixing ratios from SE (155 ppb) than from NW (135 ppb) due to advection of pollution from the highly industrialized Po Valley (Reimann et al., 2008). Strongest effects are seen for the short-lived, anthropogenic $\mathrm{NO}_{2}$ (Fig. 16). Substantially enhanced values from the more polluted sectors NE for HPB ( $>3.5 \mathrm{ppb})$ and $\mathrm{SE}$ for JFJ ( $>0.4 \mathrm{ppb}$ ) compared to the cleaner sectors WSW at HPB (2 ppb) and NW at JFJ (0.25 ppb) clearly distort the distribution of the $\mathrm{NO}_{2}-\%$-contribution curves away from the distribution of the wind directions towards more similar contributions of both sectors. For HPB this means, that 14\% of the air comes from the NE sector $\left(40-70^{\circ}\right)$ and brings $22 \%$ contribution to $\mathrm{NO}_{2}$ total signal, whereas $37 \%$ of air is from the WSW sector $\left(230-260^{\circ}\right)$ and contributes only $31 \%$ to $\mathrm{NO}_{2}$. At JFJ, the occurrence of wind directions is $48 \%$ for NW (300-330 ${ }^{\circ}$ ) and $20 \%$ for SE (130-160 ${ }^{\circ}$ ), and corresponding contributions to $\mathrm{NO}_{2}$ are $43 \%$ (NW) and $34 \%$ (SE).

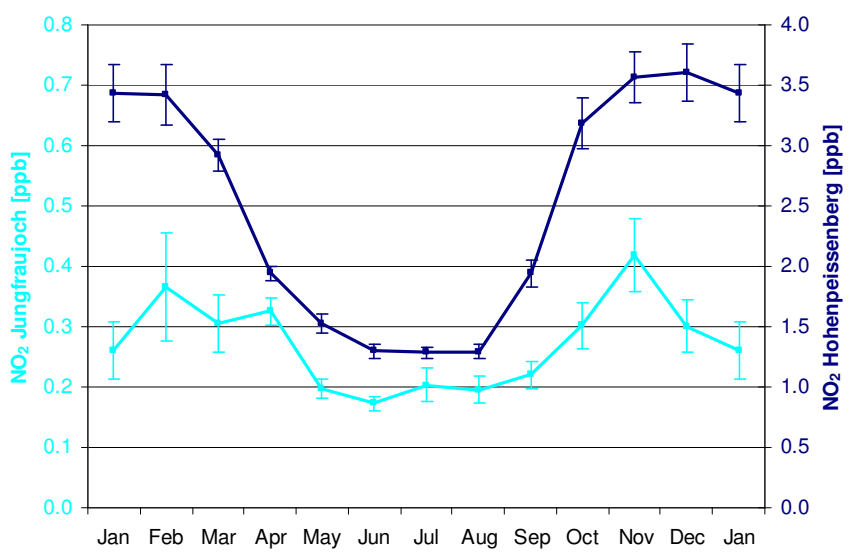

Fig. 12. $\mathrm{NO}_{2}$ mean annual variation at the "DACH" sites; dark blue: HPB; light blue: JFJ. Error bars indicate the mean error of the mean.

\section{Discussion}

In this section the implications of changing emissions, sinks, and transport for the observed features are discussed. The discussion will first focus on the primarily emitted, short lived $\mathrm{NO}_{2}$ (life-time $\sim 1$ day) to characterize local and regional anthropogenic impacts, and will go on with CO (lifetime 2 months) and associated local, regional and global effects. Finally, the secondary ozone is discussed in relation to the precursor gases $\mathrm{NO}_{2}$ and $\mathrm{CO}$. Time series of $\mathrm{NO}_{2}$ and CO for ZSF and SNB are much shorter than for the other sites and in addition there were analytical problems with $\mathrm{CO}$ at SNB, thus, the discussion will focus on the time series from JFJ and HPB.

\subsection{Nitrogen dioxide}

The time series of $\mathrm{NO}_{2}$ at JFJ and HPB show constant or declining mixing ratios (Fig. 11). Consistent downward or zero trends are also seen in the percentile distributions (Fig. 13) and data separated for the different seasons (Fig. 14). In summer, both stations show non-significant trends if the high values in 1995 and 1996 at JFJ are not considered. As the "catchment area", i.e. the area from where the emissions influencing the station are caught, is smallest in summer due to the lower life-time of $\mathrm{NO}_{2}$, the overall negative trend is not due to local but much more regional effects in emission reductions. This is supported by the fact that both sites show the smallest weekly variation in summer. A large proportion of $\mathrm{NO}_{2}$ load is already decomposed during transport to the site and corresponding exchange with reservoir species will be more important (see below).

Intensive vertical mixing in the Alpine area is most pronounced in spring and early summer and reduces the $\mathrm{NO}_{2}$ ratios between HPB and JFJ to a factor of 6 , whereas it is a factor of 8-11 in other seasons. Considering the reduced 

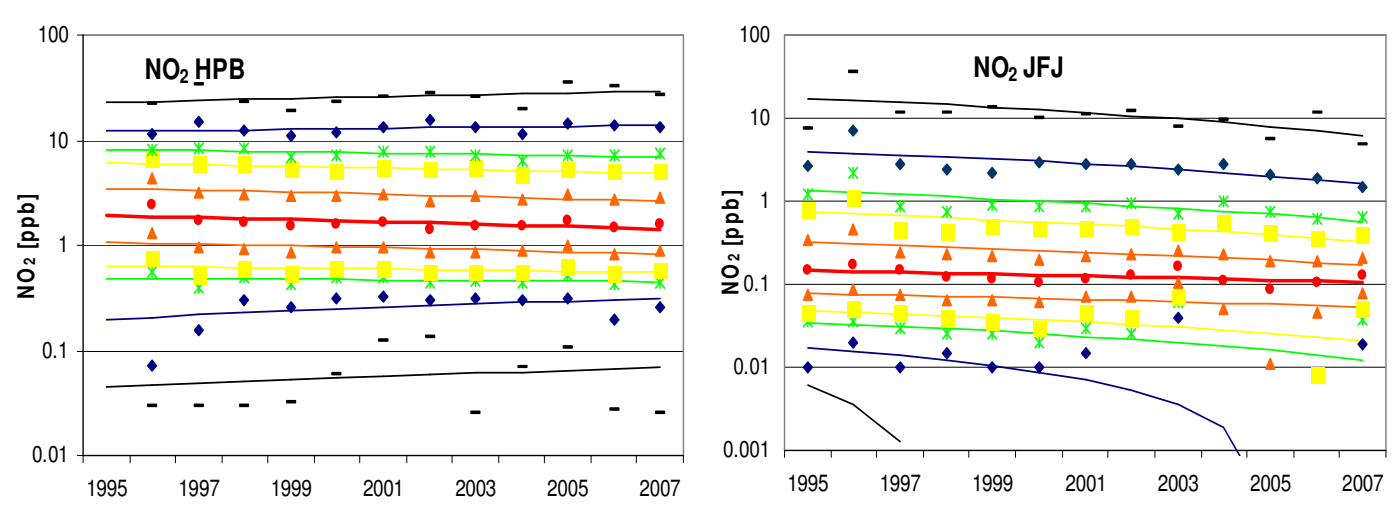

Fig. 13. $\mathrm{NO}_{2}$ time series of annual percentiles and respective linear trends at the "DACH" sites since 1995; black: minimum and maximum, blue: 1- /99- ; green: 5- /95-, yellow: 10- /90- ; orange: 25- /75-percentiles, red: median.
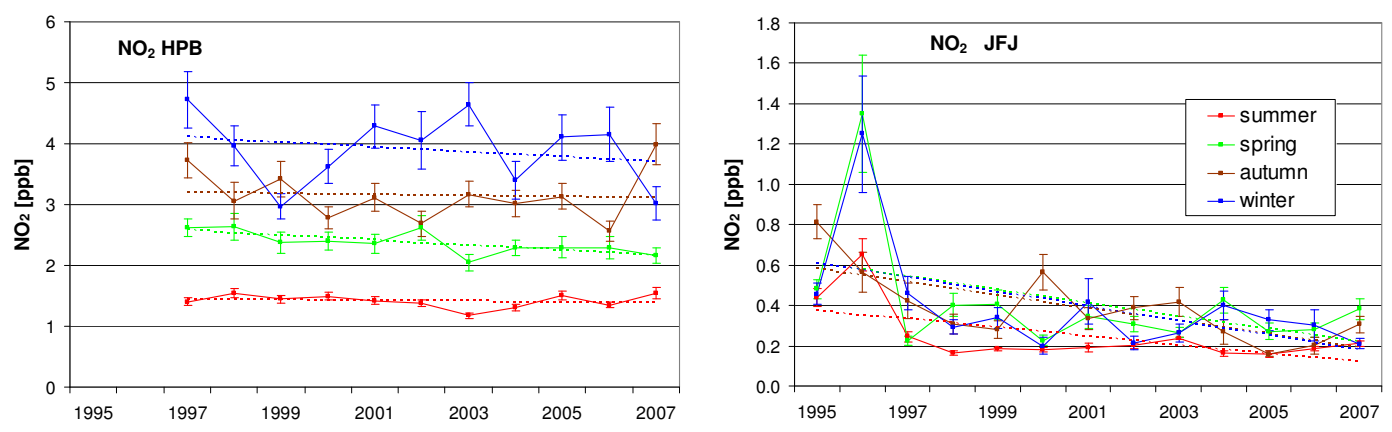

Fig. 14. $\mathrm{NO}_{2}$ time series since 1995 for the different seasons at the respective "DACH" sites; blue: winter; red: summer, brown: autumn, green: spring, yearly mean mixing ratios (solid) with standard error of the mean and linear trend (dashed).

atmospheric life-time of $\mathrm{NO}_{2}$ in summer, this indicates substantially intensified mixing (for vertical exchange, see also Zellweger et al., 2003). Nevertheless, the impact of boundary layer air on the observed mixing ratios at JFJ is clearly visible in all seasons: on working days, $\mathrm{NO}_{2}$ mixing ratios are roughly enhanced by a factor of 2 with respect to the levels on Sunday, except for summer where the factor is 1.2. These weekly cycles are similar to corresponding ratios at HPB (1.6-2).

The low amplitude in the weekly cycles of $\mathrm{NO}_{2}$ in summer compared to the other seasons may be due to stronger impacts by reservoir substances of $\mathrm{NO}_{2}$ like PAN. In summer, the turn-over of $\mathrm{NO}_{2}$ and $\mathrm{VOC}$, especially of biogenic origin, in the boundary layer is significantly enhanced with the result of higher production rates of PAN and other organonitrates. These may have life-times considerably longer than $\mathrm{NO}_{2}$ which often depend on temperature and solar irradiation. Accordingly, in summer and at elevated sites like JFJ there have been reported higher levels of PAN (Zellweger et al., 2003) and consequently higher contributions to abundant $\mathrm{NO}_{2}$ from reservoir species like PAN are expected compared to other seasons. This will then result in reduced weekly cycles as observed at JFJ. Cluster analysis of 15-days backward trajectories have also shown that long-term transport at JFJ plays a considerable role in all seasons (Balzani-Lööv et al, 2008) resulting in a masking of (regionally driven) weekly cycles.

As $\mathrm{NO}_{2}$ mixing ratios are strongly dependent on the respective wind sector (Fig. 16) trends in the observed mixing ratios might also be due to changing distributions of the wind directions. Figure 17 demonstrates that indeed at JFJ there is a declining fraction of winds coming from the "clean" NW sector (48\% in 1995 and 36\% in 2006; trend $-1.0 \% \pm 1.2 \%$ non-significant). At the same time the percentage of air coming from the more polluted SE sector which is influenced by the highly industrialized Po valley area increases (from 22 to $35 \%$; trend $+0.5 \% \pm 0.5 \%$ ). However, mixing ratios decline in both main wind sectors (only for $\mathrm{O}_{3}$ from SE sector non significant) and the shift in wind direction distribution just reduces the rate of decline in the overall JFJ time series compared to the trends in the individual sectors. At HPB (Fig. 17, left column), a decline of $\mathrm{NO}_{2}$ is observed in the main wind direction WSW ( $-0.054 \pm 0.018 \mathrm{ppb} / \mathrm{a}$, significant), whereas no statistically significant change is observed in the NE sector $(0.024 \pm 0.080 \mathrm{ppb} / \mathrm{a})$. It is interesting to note that at HPB, unlike at JFJ, the higher polluted NE sector does not show declining mixing ratios and accordingly an indication of declining emissions. At HPB, the WSW sector with much lower anthropogenic sources - and thus more representative 

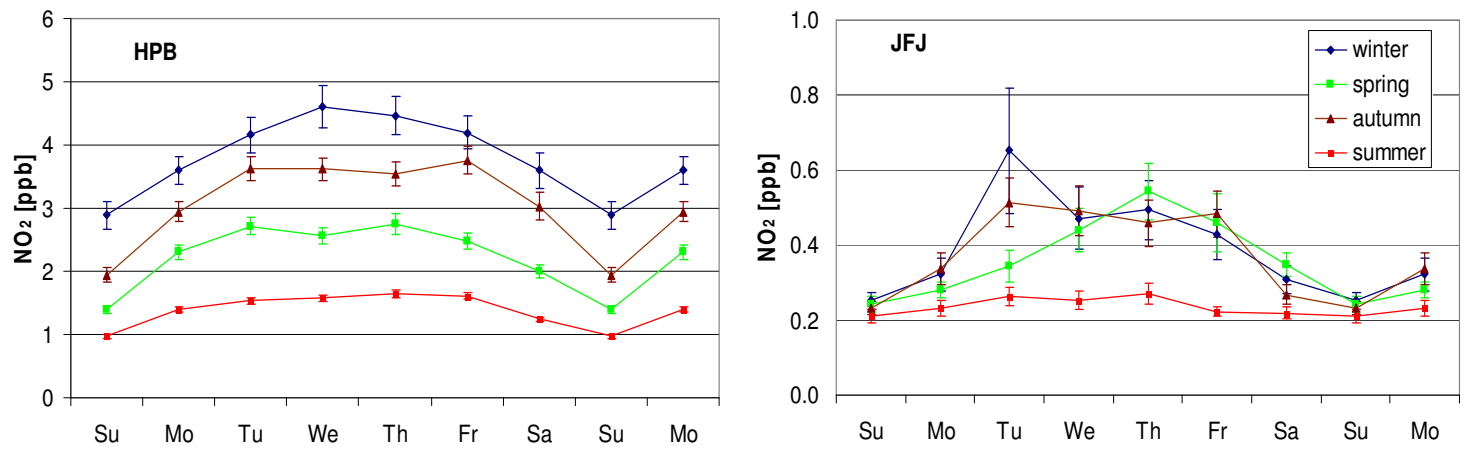

Fig. 15. Weekly variation of $\mathrm{NO}_{2}$ for the different seasons at the respective "DACH" sites, blue: winter; red: summer, brown: autumn, green: spring. The errors bars indicate the standard error of the mean.

for Central European rural boundary layer air - shows a statistically significant decline.

Under the assumptions of negligible $\mathrm{NO}_{2}$ hemispheric background values and no shift in the pattern of local sources, the observed trends in mixing ratios may be directly compared to trends in emission estimates. This is justified for the short lived $\mathrm{NO}_{2}$, as the lower percentiles and weekly cycles do generally not show indications of discernable background impact. Trends are discussed for the time interval 19972007 since $\mathrm{NO}_{2}$ mixing ratios at JFJ were unusually high in 1996 and sensitive $\mathrm{NO}_{\mathrm{x}}$ measurements at $\mathrm{HBP}$ started in 1997. From the station data considered here, $\mathrm{NO}_{2}$ in central European air tends to decline in the boundary layer and the free troposphere, indicating a mixed picture of unchanged or slightly reduced emissions in major areas of central Europe. The observed rates of decline are $-0.7 \% / y$ for HPB and $-1.6 \% / y$ for JFJ. Downward trends in the range between not detectable and $-5 \% / y r$ have been reported for stations of the NABEL network (Swiss ambient air monitoring network) in the 1990s in Switzerland (Brönnimann et al., 2002), and for European EMEP stations between 1990 and 2002 (Jonson et al., 2006). On the other hand, emission reductions in the Europe-27 area have been estimated to be $-29 \%$ $(-2.2 \% / y r)$ between 1990 and 2002 (EEA 2009) which are generally consistent with these observed rates of decline in the 90ies. Between 1995 and 2007, emissions from European countries (Europe-27) were estimated to have declined by $25 \%(-1.9 \% / \mathrm{yr})(\mathrm{EEA}, 2009)$, which is larger than the observed trends in mixing ratios.

Trends differ in the main wind sectors of a given station and can be attributed to source areas. At JFJ, $\mathrm{NO}_{2}$ mixing ratios from the SE sector decline by about $-4.1 \% / \mathrm{yr}$ and thus exceed the Italian emission estimate change for $\mathrm{NO}_{\mathrm{x}}$ of $-3.0 \%$ for $1995-2007$ (EEA 2009b). In the clean sector at $\mathrm{JFJ}(\mathrm{NW})$, the trend of $-1.5 \% / \mathrm{yr}$ is only half of the respective emission reduction estimate of about $-3 \% / \mathrm{yr}$ in Switzerland (Brönnimann et al., 2002) and $-3.7 \% / y r$ in France (EEA 2009). German $\mathrm{NO}_{2}$ emissions are estimated to have declined by $-3.0 \% / \mathrm{yr}$ which is far more than observed at HPB.
Here, especially the more polluted NE sector shows slightly increasing mixing ratios of $+0.5 \% / y r$, whereas the decline in the WSW sector of $-1.8 \% / \mathrm{yr}$ is still smaller than the estimated change in emissions.

Sites influenced by local traffic, e.g. selected NABEL sites in Switzerland, show more pronounced downward trends of typically $3-5 \% / y r$ compared to elevated and more or less remote sites, e.g. Rigi and Chaumont, with negative trends between 0 and 1\%/yr (Brönnimann et al., 2002). Thus, there remains a yet unresolved discrepancy between the trends at sites impacted by local traffic which are often consistent with emission reduction estimates, and the more remote and elevated sites, representative for a lager area, with much smaller rates of decrease not in line with European emission reductions.

\subsection{Carbon monoxide}

All time series show declining signals independent of season (Figs. 7 and 10). The percentile distributions have narrowed at all sites by consistently declining levels of the higher percentiles (Fig. 9). No significant weekly variations for $\mathrm{CO}$ are observed, as expected due to its considerably longer life time ( 2 months). This fact and the declining higher percentiles indicate no strong local impacts on the measurements at the respective sites.

Annual cycles show similar patterns with maxima in late winter and minima in late summer for all stations (Fig. 8), mainly due to the annual cycle of the only sink for $\mathrm{CO}$, i.e. the reaction with $\mathrm{OH}$ radicals (Novelli et al., 2003). As for $\mathrm{NO}_{2}$, the effect of intensive vertical mixing in late spring and summer (April-July) becomes obvious in the very similar mixing ratios at both the lowest (HPB) and the high Alpine sites. In the other seasons, boundary layer air with higher mixing ratios and less pronounced vertical mixing cause the higher values at HPB. Occasionally in winter time at HPB, persistent inversion layers over several days can additionally contribute to enhanced mixing ratios. This effect might partly explain the shift in the annual cycle with 

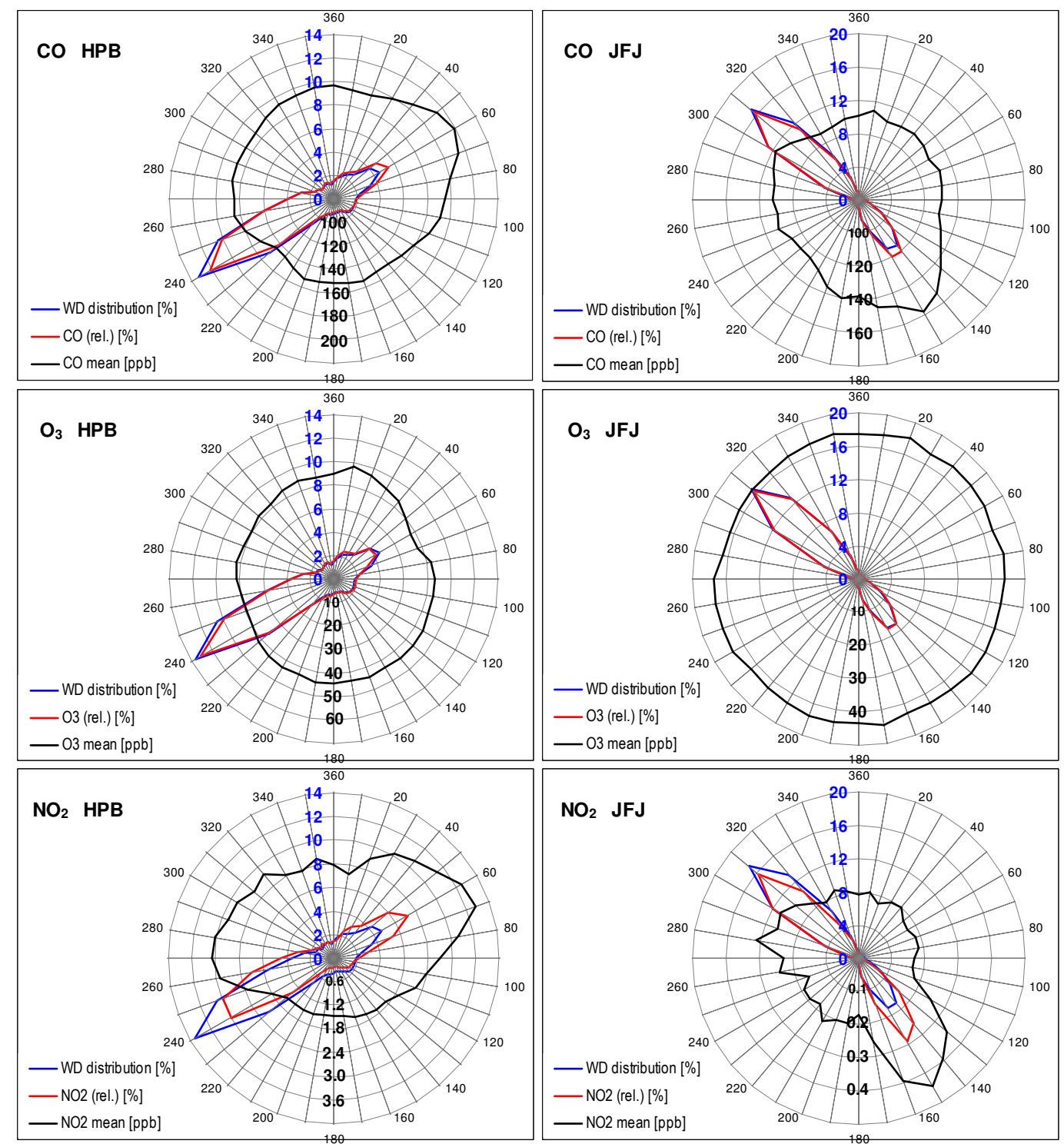

Fig. 16. Dependence of $\mathrm{CO}, \mathrm{O}_{3}, \mathrm{NO}_{2}$ on wind direction for station $\mathrm{HPB}$ (left column) and JFJ (right column): Mean of respective trace gas per $10^{\circ}$ wind direction interval (black), relative frequency of wind direction (blue) and relative abundance of the respective trace gas, weighted by frequency of wind direction (red). The latter one is calculated by first multiplying the respective mean mixing ratio and the wind frequency in a given $10^{\circ}$ sector, and then normalizing these numbers by the corresponding integral over all wind sectors.

a maximum in February compared to April for the high elevated stations. The late seasonal maximum (April) for $\mathrm{CO}$ is partly due to a specific feature of $\mathrm{CO}$ : it is not only a primarily emitted trace gas but also secondarily produced through atmospheric oxidation of methane and VOC. As this is determined by the product of $\mathrm{OH}$ and the respective organics concentration, this production pathway gets highly efficient in spring when the winter burdens of the organic precursors are converted to $\mathrm{CO}$ and other products (Gros et al., 2001). Miller et al. (2008) concluded from their analysis of highly time resolved series of $\mathrm{CO}$ and other trace gas measurements including $\mathrm{HCHO}$ that for North America the $\mathrm{CO}$ source re- lated to combustion had been overestimated and the secondary source from atmospheric oxidation of organic trace gases underestimated. Especially, the latter was considered to be the main source in summer. The primary sources, fossil fuel combustion and biomass burning, are considered to peak in late winter (Gros et al., 2001). Also most probably due to vertical mixing effects, both the winter and spring values differ at HPB (as well as the autumn and summer values) whereas they are similar at the higher stations: intensive vertical mixing in late spring and in summer reduces the levels at HPB and enhances them at the high elevated sites. In contrast, in autumn and winter the impact of boundary layer air 

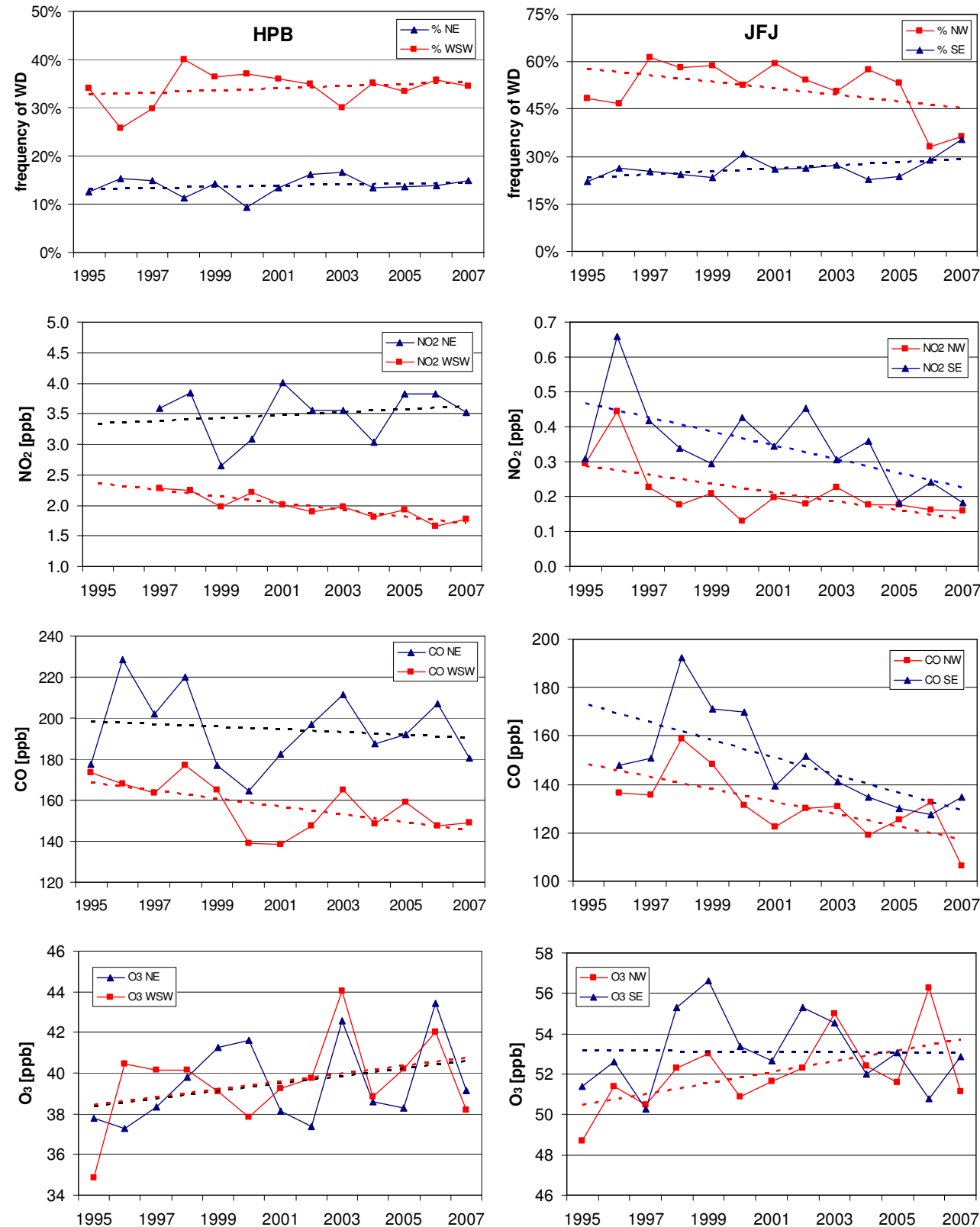

Fig. 17. Time series (1995-2007) at HPB (left column) and JFJ (right column) for the main wind sectors: (a) frequency of wind direction, (b) $\mathrm{O}_{3}$, (c) $\mathrm{CO}$ and (d) $\mathrm{NO}_{2}$ mixing ratios.

on the higher sites becomes less pronounced again. Thus, the April maximum at the high sites is attributed to a combination of all these factors.

Gradients between the low and high Alpine stations tend to increase over time, as the decline at the higher site JFJ is stronger than at the lower site HPB. Taking into account that gradients of the short-lived $\mathrm{NO}_{2}$ do not change in time, there are no indications of increased vertical mixing between 1000 and $3600 \mathrm{~m}$ over the time period considered here (19952007).
Similar as for $\mathrm{NO}_{2}$, mixing ratio levels are different in the main wind sectors (only discussed for HPB and JFJ with their longer time series compared to SNB and ZSF). The "more polluted" sectors (SE at JFJ and NE at HPB) show higher mixing ratios than the "cleaner" sectors. The rate of decline is highest (ca. $-2.0 \% / \mathrm{yr}$ ) for the SE sector at JFJ, the "clean" NW sector at JFJ shows $-1.6 \% / \mathrm{yr}$; the WSW sector at HPB a trend of about $-1.0 \% / y r$, and the "more polluted" sector NE at HPB a weak and non-significant trend of $-0.3 \% / y$. Zellweger at al. (2009) have given an overall trend of $-2.2 \% / \mathrm{yr}(-3.32 \mathrm{ppb} / \mathrm{yr})$ for JFJ $(1996-2007)$ 
for the same data set as used in this study. After applying a meteorological filter criterion to select free tropospheric air they obtained $-1.8 \% / y r$. They also pointed out that this trend is substantially lower (about half) than for stations from the NABEL network in Switzerland (Zellweger et al., 2009) and compared to emission estimates of EEA (2009 (2)). Significantly lower trends were reported for Zugspitze with $-0.84 \mathrm{ppb} / \mathrm{yr}$ for the period 1991-2004 (Chevalier et al., 2008). There are no pronounced seasonal differences at JFJ (summer: $-3.25 \pm 1.42$; spring $-3.52 \pm 1.99$; autumn: $-3.77 \pm 2.16$, winter: $-2.70 \pm 2.12 \mathrm{ppb} / \mathrm{a}$, all significant at the $95 \%$ confidence level) with lowest trends in winter. This is similar to our findings at ZUG with also the lowest trend in winter $(-0.95 \pm 2.34-\mathrm{ppb} / \mathrm{a}$, non-significant), but different from seasonal trends at Zugspitze found by Chevalier et al. (2008) with the most pronounced downward trends between January and April for the period 1991-2004. Overall, trends at JFJ are half of those at lower sites in Switzerland, and they are strongly influenced by southerly air masses (potentially from Italy), and they are much larger than trends observed at the northern sites Zugspitze and HPB of about $-1 \% / y r$ or less. Furthermore, at JFJ the FTIR data reveal a trend of the CO column density between JFJ and $7 \mathrm{~km}$ of $-1 \mathrm{ppb} / \mathrm{yr}$ (ca. $-0.7 \% / \mathrm{yr}$ ) for the period 1997-2005 (Dils et al., 2009). If the southerly sector at JFJ is not considered, trends from all observations are comparable, suggesting an impact of polluted, southerly air at JFJ that is not experienced at higher elevations (FTIR) and at the other sites (ZUG and HPB).

A common feature of the $\mathrm{CO}$ percentile distributions are the mixed and non-significant changes in the lower percentiles as presented in Sect. 3, Fig. 9. As these are largely determined by clean and fast advected free tropospheric air from the Atlantic, the observations indicate no continuous changes in the background mixing ratios over the time period under investigation, i.e. 1995-2007. However, the lower percentiles of all stations indicate enhanced values in 1996, 1998 and 2003, at JFJ and ZSF also in 2002. These correspond to well documented rises in background $\mathrm{CO}$ due to biomass burning in boreal forest areas of Asia and North America in 1996, 1998 and 2002, 2003 (e.g. Yurganov et al., 2004 and 2005; Zellweger et al., 2009; Meszaros et al., 2005).

Thus, the data analysed in this study imply no consistent change in background levels of $\mathrm{CO}$ but declining average mixing ratios and associated emissions depending on source areas. North Italian emissions appear to show the strongest decline whereas for westerly sectors with cleaner air (at JFJ and HPB) moderate but still significant declines are observed. Finally, the NE sector at HPB with emission impact from Munich and Eastern European countries shows no significant change for $\mathrm{CO}$ and $\mathrm{NO}_{2}$.

\subsection{Ozone}

Ozone is the only purely secondary trace gas considered here. Accordingly, discussion of the observed features is more complex and has to consider also changes in the precursor gases $\mathrm{NO}_{2}$ and $\mathrm{CO}$.

The pronounced increase in ozone observed at all sites since the 1970's (Fig. 1) levels off at all stations and becomes non-significant after 1995 (Fig. 2), as reported in previous studies (Oltmans et al., 2006; Vingarzan (2004); Derwent, 2007). Seasonally separated time series show non-significant changes except a significant but slightly increasing trend in winter at JFJ and HPB (Fig. 5). Similarly, in previous studies, the most pronounced increases were observed in winter but also in autumn and spring, and unchanged or reduced levels in summer (e.g. Oltmans et al., 2007; Zbinden et al., 2006). There is a consistent offset of $10-15$ ppb between the low site HPB and the high Alpine sites, also seen in the mean annual cycles (Fig. 3) (see also Chevalier et al., 2007; Brönnimann et al., 2000). As already discussed for $\mathrm{NO}_{2}$ and $\mathrm{CO}$, the levels at the different elevations are closest in late spring and summer, due to intensive vertical mixing at this time of the year. In autumn and winter, HPB shows lowest levels compared to the other sites, mostly due to less pronounced vertical mixing and accordingly stronger effects of boundary layer ozone sinks including deposition and titration by $\mathrm{NO}\left(\mathrm{NO}+\mathrm{O}_{3} \rightarrow\right.$ $\mathrm{NO}_{2}+\mathrm{O}_{2}$ ).

Titration effects play a role at all stations. This assumption is supported by weekly cycles with lower $\mathrm{O}_{3}$ mixing ratios during working days and maxima on the weekend in autumn and winter (Fig. 6). This pattern is anti-correlated with that of $\mathrm{NO}_{2}$ (Fig. 15). Contrary, photochemical ozone production in summer, mainly in the boundary layer, might also have contributed to lower vertical gradients in summer ozone. The weekly cycles clearly demonstrate the impact of anthropogenic precursors on ozone production. Similar weekly variations were observed in the UK and attributed to air masses influenced by anthropogenic emissions for several days (Jenkin, 2002). The range of variation in summer is up to $2 \mathrm{ppb}$ higher ozone mixing ratios at the mid of the week (Fig. 6) with the strongest effect at HPB, the station most influenced by boundary layer air. Accordingly, $\mathrm{O}_{3}$ titration effects mainly in winter and $\mathrm{O}_{3}$ production in summer are observed at all stations with smaller effects at the high elevated sites due to the diminishing impact of surface emissions.

Correlations at HPB support these photo-chemical interactions: In all seasons except summer, $\mathrm{O}_{3}$ is anticorrelated with $\mathrm{NO}_{2}$ (not shown) and suggests ozone destruction due to reaction with $\mathrm{NO}$ to be an important loss mechanism for $\mathrm{O}_{3}$ in the boundary layer. Only in summer, the correlation with $\mathrm{NO}_{2}$ turns non-significantly positive and a similar correlation with $\mathrm{CO}$ becomes significantly positive, whereas $\mathrm{O}_{3} \sim \mathrm{CO}$ correlations are non-significant or anticorrelated in other seasons. This indicates that only in summer the boundary layer net photochemical ozone production is linked to 
regional anthropogenic emissions, in other seasons anthropogenic emissions tend to suppress ambient ozone at the Alpine mountain sites considered in this study. At JFJ, Brönnimann et al. (2000) also demonstrated a positive correlation between $\mathrm{O}_{3}$ and $\mathrm{CO}$ in summer and no clear correlation in autumn and winter.

The absence of significant trends in ozone for the last 12 years leads to the assumption of unchanged ozone mixing ratios during the recent years. This may be due either to unchanged sources, sinks, and transport at the four stations or to compensating effects in two or more of these factors. Trends in the corresponding percentile time series can principally help to identify contributing effects (Jenkin, 2008). However, the percentile distributions show neither strong nor significant features, just tendencies: All four stations show gentle increases in the time series of most of the lower percentile classes up to the medians. While this tendency persists for the higher percentile classes at JFJ, it gradually levels off at the other sites, with declines only in the maxima at SNB and HPB and in the upper percentiles at ZSF (Fig. 4). Thus, there are indications for slightly declining local and regional photochemical ozone sources as the maxima or/and higher percentiles fall at three of the sites. On the other side, there are indications for increasing background levels as most of the percentiles tend to rise, and at JFJ and SNB with very similar rates for all or at least most of the percentiles. And, there are indications for lower local and regional sinks as the rates of increase tend to be highest for the lower percentiles of the distributions at the sites HPB and ZSF. The latter interpretation would in principal be consistent with the observed, slightly negative trends for $\mathrm{NO}_{2}$. Additionally traffic emissions have changed with lower percentages of NO versus NOx emissions nowadays compared to high values some 15 years ago. Accordingly, the amount of freshly emitted $\mathrm{NO}$ has been more substantially reduced compared to $\mathrm{NO}_{2}$, and the corresponding negative impact on ozone levels is expected to have declined in the last 15 years.

Changes in vertical transport with corresponding impacts on ozone can not be discerned from the available data. As already lined out above, $\mathrm{NO}_{2}$ and $\mathrm{CO}$ vertical gradients show no clear trends in time, just for $\mathrm{CO}$ a slight tendency of stronger gradients and associated lower vertical mixing might be inferred. However, vertical gradients in ozone between HPB and JFJ did not change, and between HPB and SNB or ZSF, if at all, slightly weaker gradients appear to develop. This would imply no change or slightly enhanced vertical mixing which, however, is in contrast to the analysis of the other trace gases.

As the distributions of ozone with wind direction do not show strong changes especially in the main wind sectors (Figs. 16-17), no strong effects due to changing wind directions in the period considered can be expected. Accordingly, $\mathrm{O}_{3}$ levels and trends in the 2 main wind sectors at HPB are not significantly different from one another (Fig. 17). Although both $\mathrm{NO}_{2}$ levels and trends are different in the corre- sponding sectors, no discernable effect on ozone levels and trends due to changing chemistry at the encountered precursor levels are detected.

In contrast to the observation of unchanging ozone mixing ratios at the four alpine mountain sites, negative trends are observed at $3 \mathrm{~km}$ above ground from ozone soundings in Central Europe (e.g. Claude et al., 2004). This can not be attributed to a simple surface-boundary layer effect of the mountain sites considered in this study since the MOZAIC results of airborne measurements also result in slightly positive trends ( 0 to $2 \% / y r)$ for the 1995-2001 period at Frankfurt and Paris (Zbinden et al., 2006) and also in the upper troposphere over Western Europe.

\section{Conclusions}

Slightly decreasing mixing ratios of the primary trace gases $\mathrm{NO}_{2}$ and $\mathrm{CO}$ are observed at all stations between 1995 and 2007. The findings are generally consistent at the four alpine mountain stations and thus are considered to represent regional changes in Central European atmospheric composition at elevations $\geq 1000 \mathrm{~m}$. The observed rates of decline at the alpine mountain stations, however, do not follow the national emission estimates: For $\mathrm{NO}_{2}$, reductions by 0 to $-2 \% / \mathrm{yr}$ are measured at JFJ (NW sector) and HPB which is substantially less than corresponding rates of change in national emission estimates (EEA, 2009) which are in the order of -3 to $-5 \% / \mathrm{yr}$ for most of the Central European states contributing to EU-27. For CO, again the emission estimates have declined by some $50 \%$ for the period 1990 2007 , corresponding to current average changes of $-5.8 \% / \mathrm{yr}$ (2006-2007). Likewise, the observed mixing ratios at the alpine stations decline by $0-1 \% / \mathrm{yr}$ for HPB and some $2 \% / \mathrm{yr}$ for JFJ. While for the long-lived $\mathrm{CO}$ these observations are principally consistent with decreasing emissions from $\mathrm{Eu}-$ rope and long-range transport with increasing emissions predominantly from Asia (Pfister et al., 2004), there remains a discrepancy for $\mathrm{NO}_{2} . \mathrm{NO}_{2}$ is too short lived (1 day) that long-range transport from other continents can have an impact on the European atmospheric composition. Still, on European scales, episodes of trans-boundary transport can be observed (Schaub et al., 2005; Kaiser et al., 2007). However, these episodes occur mainly in winter when life-time of $\mathrm{NO}_{2}$ is longest. In summer, however, significant downward $\mathrm{NO}_{2}$ trends are not observed. Thus, current $\mathrm{NO}_{2}$ emission estimates are not consistent with the observations at the DACH alpine mountain stations. This hints towards an overestimate of emission reductions in the EU.

Over the same period 1995-2007, the $\mathrm{O}_{3}$ mixing ratios have slightly increased at three of the four sites. This was observed independent of wind sector and for most seasons, with a tendency to higher positive trends in winter and lower, partly negative trends in summer. This is consistent with previous findings (Oltmans et al., 2006). Indications for local 
and regional photochemical production of ozone from precursors including $\mathrm{NO}_{2}$ and $\mathrm{CO}$ were only observed in summer, and less pronounced in spring. However, results from these $\mathrm{O}_{3}$ precursors are not consistent for all stations and their relations will have to be analyzed in more detail.

Apart from photochemical production, changes in vertical exchange processes might significantly impact the observed trends. However, based on the precursors $\mathrm{NO}_{2}$ and $\mathrm{CO}$ at the differently elevated stations, no indications for enhanced vertical mixing between boundary layer and lower free troposphere could be discerned. Accordingly, changes in vertical mixing between boundary layer and free troposphere can not be responsible for enhanced $\mathrm{O}_{3}$ and simultaneously decreased $\mathrm{CO}$ at the lower site. On the contrary, increasing mixing within the free troposphere could result in enhanced $\mathrm{O}_{3}$ and reduced $\mathrm{CO}$ levels in the lower free troposphere, with according implications down to the boundary layer. This phenomenon will be further discussed by Kaiser et al. (2010).

Acknowledgements. The authors would like to thank our colleagues of the German Meteorological Service, Hohenpeissenberg Meteorological Observatory, the German Environmental Agency, Schneefernerhaus Station, the Central Institute for Meteorology and Geophysics, Enviromental Meteorology, Austria and the Environmental Agency Austria, making this study possible by their continuous technical and engineering support.

The Swiss National Air Pollution Monitoring Network is run by Empa in joint collaboration with the Swiss Federal Office for the Environment. We thank the International Foundation High Altitude Research Station Jungfraujoch and Gornergrat (HFSJG) for access to Jungfraujoch facilities. The provision of meteorological data at JFJ by MeteoSwiss is highly acknowledged.

Edited by: A. Hofzumahaus

\section{References}

Balzani-Lööv, J. M., Henne, S., Legreid, G., Staehelin, J., Reimann, S., Prevot, A. S. H., Steinbacher, M., and Vollmer, M. K.: Estimation of background concentrations of trace gases at the Swiss Alpine site Jungfraujoch (3580 m a.s.1.), JGR, 113, D22305, doi:10.1029/2007JD009751, 2008.

Brönnimann, S., Schuepbach, E., Zanis, P., Buchmann, B., and Wanner, H.: A climatology of regional background ozone at different elevations in Switzerland (1992-1998), Atmos. Environ., 34(29-30), 5191-5198, 2000.

Brönnimann, S., Buchmann, B., and Wanner, H.: Trends in near surface ozone concentrations in Switzerland: the 1990s, Atmos. Environ., 36(17), 2841-2852, 2002.

Buchmann, B., Klausen, J. and Zellweger, C.: Traceability of LongTerm Atmospheric Composition Observations across Global Monitoring Networks, Chimia, 63(2009), doi:10.2533/chimia, 2009.
Carslaw, D. C.: On the changing seasonal cycles and trends of ozone at Mace Head, Ireland, Atmos. Chem. Phys., 5, 34413450, doi:10.5194/acp-5-3441-2005, 2005.

Chevalier, A., Gheusi, F., Delmas, R., Ordóñez, C., Sarrat, C., Zbinden, R., Thouret, V., Athier, G., and Cousin, J.-M.: Influence of altitude on ozone levels and variability in the lower troposphere: a ground-based study for western Europe over the period 20012004, Atmos. Chem. Phys., 7, 4311-4326, doi:10.5194/acp7-4311-2007, 2007.

Chevalier, A., Gheusi, F., Attié, J.-L., Delmas, R., Zbinden, R., Athier, G., and Cousin, J.-M.: Carbon monoxide observations from ground stations in France and Europe and long trends in the free troposphere, Atmos. Chem. Phys. Discuss., 8, 3313-3356, doi:10.5194/acpd-8-3313-2008, 2008.

Colette, A. and Ancellet, G.: Impact of vertical transport processes on the vertical layering of tropospheric ozone above Europe. Part II: Climatological analysis of the last 30 years, Atmos. Environ., 39, 5423-5435, 2005.

Colette, A., Ancellet, G., and Borchi, F.: Impact of vertical transport processes on the vertical layering of tropospheric ozone above Europe. Part I: Study of air mass origin using multi-variate analysis and clustering, Atmos. Environ., 39, 5409-5422, 2005.

Derwent, R. G., Jenkin, M. E., Saunders, S. M., Pilling, M. J., Simmonds, P. G., Passant, N. R., Dollard, G. J., Dumitrean, P., and Kent, A.: Photochemical ozone formation in north west Europe and its control, Atmos. Environ., 37, 1983-1991, 2003.

Derwent, R. G., Simmonds, P. G., O'Doherty, S., Stevenson, D. S., Collins, W. J., Sanderson, M. G., Johnson, C. E., Dentener, F., Cofala, J., Mechler, R., and Amann, M.: External influences on Europe's air quality: baseline methane, carbon monoxide and ozone from 1990 and 2030 at Mace Head, Ireland, Atmos. Environ., 40, 844-855, 2006.

Derwent, R. G., Simmonds, P. G., Manning, A. J., and Spain, T. G.: Trends over a 20-year period from 1987 to 2007 in surface ozone at the atmospheric research station, Mace Head, Ireland, Atmos. Environ., 41, 9091-9098, 2007.

Derwent, R., Stevenson, D., Collins, W., and Johnson, C.: Intercontinental transport and the origins of the ozone observed at surface sites in Europe, Atmos. Environ., 38(13), 1891-1901, 2004.

Dils, B., Demoulin, P., Mahieu, E., Steinbacher, M., Buchmann, B. and De Mazière, M.: Ground-based CO observations at the Jungfraujoch from 1997 till 2007: Comparison between FTIR and NDIR measurements, Geomon annual meeting, Genève, 2629 January 2009, http://hdl.handle.net/2268/16041, 2009.

Duncan, B. N., Logan, J. A., Bey, I., Megretskaia, I. A., Yantosca, R. M., Novelli, P. C., Jones, N. B., and Rinsland, C. P.: Global budget of CO, 1988-1997: Source estimates and validation with a global model, J. Geophys. Res. Atmos., 112, D22301, doi:10.1029/2007JD008459, 2007.

EEA: Assessment of ground-level ozone in EEA member countries, with a focus on long-term trends, Technical Report No 7/2009, EEA (European Environment Agency), ISBN 978-92-9213-0039, 2009. (1)

EEA: European Community emission inventory report 1990-2007 under the UNECE Convention on Long-range Transboundary Air Pollution (LRTAP), Technical Report No 8/2009, EEA (European Environment Agency), ISBN 978-92-9213-005-3, 2009. (2)

Fischer, H., Lawrence, M., Gurk, Ch., Hoor, P., Lelieveld, J., Heg- 
glin, M. I., Brunner, D., and Schiller, C.: Model simulations and aircraft measurements of vertical, seasonal and latitudinal $\mathrm{O} 3$ and CO distributions over Europe, Atmos. Chem. Phys., 6, 339-348, doi:10.5194/acp-6-339-2006, 2006.

Forrer, J., Rüttimann, R., Schneiter, D., Fischer, A., Buchmann, B., and Hofer, P.: Variability of trace gases at the high-Alpine site Jungfraujoch caused by meteorological transport processes, J. Geophys. Res., 105(D10), 12241-12251, 2000.

GAWSIS: GAW Station Information System: http://gaw.empa.ch/ gawsis, 2009.

Gerbig, C., Schmitgen, S., Kley, D., Volz-Thomas, A., Dewey, K., and Haaks, D.: An improved fast-response vacuum-UV resonance fluorescence CO instrument, J. Geophys. Res.-Atmos., 104, 1699-1704, 1999.

Gilge, S.: Quality Assurance of long-term CO Measurements, Poster at Joint WMO/GAW-Accent Workshop, EMPA Duebendorf, Switzerland, (http://www.empa.ch/plugin/template/empa/ */43919), 2005.

Gomiscek, B., Ciglar, R., Scheel, H. E., and Veber, M.: Analysis of the Ozone Spring Maximum at the Krvavec Elevated TOR Site, in: Eurotrac Vol 1, Transaction: Ecology and the Environment, Volume 35, Online ISSN: 1743-3541, Print ISBN: 1-85312-6780, edited by: Borrell, P. M., EUROTRAC-2 International Scientific Secretariat, Germany, Pages: 856, Published: 1999.

Gros, V., Bonsang, B., Martin, D., Novelli, C. P., and Kazan, V.: Carbon monoxide short term measurements at Amsterdam island: estimations of biomass burning emission rates, Chemosphere - Global Change Science, 1(1-3), 163-172, 1999.

Henne, S., Furger, M., Nyeki, S., Steinbacher, M., Neininger, B., de Wekker, S. F. J., Dommen, J., Spichtinger, N., Stohl, A., and Prévôt, A. S. H.: Quantification of topographic venting of boundary layer air to the free troposphere, Atmos. Chem. Phys., 4, 497509, doi:10.5194/acp-4-497-2004, 2004.

Honrath, R. E., Owen, R. C., Val Martin, M., Reid, J. S., Lapina, K., Fiahlo, P., Dziobak, M. P., Kleissel, J., and Westphal, D. L.: Regional and hemispheric impacts of anthropogenic and biomass burning emissions on summertime $\mathrm{CO}$ and $\mathrm{O}_{3}$ in the North Atlantic lower free troposphere. J. Geophys. Res.-Atmos., 109, D24310, doi:10.1029/2004JD005147, 2004.

Jenkin, M. E., Davies, T. J., and Stedman, J. R.: The origin and day-of-week dependence of photochemical ozone episodes in the UK, Atmos. Environ., 36, 999-1012, 2002.

Jenkin, M. E.: Analysis of the sources and partitioning of oxidant in the UK. Part 1: The $\mathrm{NO}_{\mathrm{x}}$-dependence of annual mean concentrations of nitrogen dioxide and ozone, Atmos. Environ., 38, 5117-5129, 2004.

Jenkin, M. E.: Trends in ozone concentration distributions in the UK since 1990: Local, regional and global influences, Atmos. Environ., 42, 5434-5445, 2008.

Jonson, J. E., Simpson, D., Fagerli, H., and Solberg, S.: Can we explain the trends in European ozone levels?, Atmos. Chem. Phys., 6, 51-66, doi:10.5194/acp-6-51-2006, 2006.

Kaiser, A., Scheifinger, H., Weiss, A., Gilge, S., Ries, L., Cemas, D., and Jesenovec, B.: Transport of nitrogen oxides, carbon monoxide and ozone to the Alpine Global Atmosphere Watch stations Jungfraujoch (Switzerland), Zugspitze and Hohenpeissenberg (Germany), Sonnblick (Austria) and Mt. Krvavec (Slovenia), Atmos. Environ., 41, 9273-9287, doi:10.1016/j.atmosenv.2007.09.027, 2007.
Meszaros, T., Haszpra, L., and Gelencser, A.: Tracking changes in carbon monoxide budget over Europe between 1995 and 2000, Atmos. Environ., 39, 7297-7306, 2005.

Monks, P. S.: A review of the observations and origins of the spring ozone maximum, Atmos. Environ., 34, 3545-3561, 2000.

Naja, M., Akimoto, H., and Staehelin, J.: Ozone in background and photochemically aged air over central Europe: Anlysis of longterm ozonesonde data from Hohenpeissenberg and Payerne, J. Geophys. Res., 108(D2), 4063-4073, 2003.

Novelli, P. C., Masarie, K. A., Lang, P. M., Hall, B. D., Myers, R. C., and Elkins, J. W.: Re-analysis of tropospheric CO trends: Effects of the 1997-1998 wild fires, J. Geophys. Res.-Atmos., 108, 4464, doi:4410.1029/2002JD003031, 2003.

Oltmans, S., Lefohn, A., Harris, J., Galbally, I., Scheel, H., Bodeker, G., Brunke, E., Claude, H., Tarasick, D., Johnson, B., Simmonds, P., Shadwick, D., Anlauf, K., Schmidlin, F., Fujimoto, T., Akagi, K., Meyer, C., Nichol, S., Davies, J., Redondas, A., and Cuevas, E.: Long-term changes in tropospheric ozone, Atmos. Environ., 40, 3156-3173, 2006.

Ordónez, C., Mathis, H., Furger, M., Henne, S., Hüglin, C., Staehelin, J., and Prévôt, A. S. H.: Changes of daily surface ozone maxima in Switzerland in all seasons from 1992 to 2002 and discussion of summer 2003, Atmos. Chem. Phys., 5, 1187-1203, doi:10.5194/acp-5-1187-2005, 2005.

Pfister, G., Petron, G., Emmons, L. K., Gille, J. C., Edwards, D. P., Lamarque, J. F., Attie, J. L., Granier, C., and Novelli, P. C.: Evaluation of $\mathrm{CO}$ simulations and the analysis of the CO budget for Europe, J. Geophys. Res.-Atmos., 109, doi:10.1029/2004JD004691, 2004.

Reimann, S., Vollmer, M. K., Folini, D., Steinbacher, M., Hill, M., Buchmann, B., Zander, R., and Mahieu, E.: Observations of Anthropogenic Halocarbons at the High-Alpine site of Jungfraujoch for assessment of trends and European sources, Sci. Total Environ., 391, 224-231, 2008.

Ribas, A. and Penuelas, J.: Temporal patterns of surface ozone levels in different habitats of the North Western Mediterranean basin, Atmos. Environ., 38, 985-992, 2004.

Sachs, L., Angewandte Statistik: Anwendung statistischer Methoden, 7. Aufl., Springer Verlag berlin Heidelberg, 1992, ISBN 3-540-52085-6.

Schaub, D., Weiss, A. K., Kaiser, J. W., Petritoli, A., Richter, A., Buchmann, B., and Burrows, J. P.: A transboundary transport episode of nitrogen dioxide as observed from GOME and its impact in the Alpine region, Atmos. Chem. Phys., 5, 23-37, doi:10.5194/acp-5-23-2005, 2005.

Scheel, H., Areskoug, H., Geiss, H., Gomiscek, B., Granby, K., Haszpra, L., Klasinc, L., Kley, D., Laurila, T., Lindskog, A., Roemer, M., Schmitt, R., Simmonds, P., Solberg, S., and Toupance, G.: On the Spatial Distribution and Seasonal Variation of Lower-Troposphere Ozone over Europe, J. Atmos. Chem., 28, 11-28, 1997.

Simmonds, P. G., Manning, A. J., Derwent, R. G., Ciais, P., Ramonet, M., Kazan, V., and Ryall, D.: A burning question: Can recent growth rate anomalies in greenhouse gases be attributed to large-scale biomass burning events?, Atmos. Environ., 39, 25132517, 2005.

Vautard, R., Honoré, C., Beekmann, M., and Rouil, L.: Simulation of ozone during the August 2003 heat wave and emission control scenarios, Atmos. Environ., 39, 3291-3303, 2005. 
Vestreng, V., Adams, M., and Goodwin, J.: Inventory review 2004: Emission data reported to CLRTAP and under the NEC directive, EMEP/MSC-W status report 1/04, The Norwegian Meteorological Institute, Oslo, Norway, 2004.

Vingarzan, R.: A review of surface ozone background levels and trends, Atmos. Environ., 38, 3431-3442, 2004.

WMO, WMO Global Atmosphere Watch (GAW) Strategic Plan (2008-2015), GAW Report No. 172 (WMO TD NO. 1384), World Meteorological Organization, Geneva, Switzerland, http: //gaw.empa.ch/gawsis, 2007.

Yurganov, L. N., Blumenstock, T., Grechko, E. I., Hase, F., Hyer, E. J., Kasischke, E. S., Koike, M., Kondo, Y., Kramer, I., Leung, F. Y., Mahieu, E., Mellqvist, J., Notholt, J., Novelli, P. C., Rinsland, C. P., Scheel, H. E., Schulz, A., Strandberg, A., Sussmann, R., Tanimoto, H., Velazco, V., Zander, R., and Zhao, Y.: A quantitative assessment of the 1998 carbon monoxide emission anomaly in the Northern Hemisphere based on total column and surface concentration measurements, J. Geophys. Res.-Atmos., 109, doi:10.1029/2004JD004559, 2004.

Yurganov, L. N., Duchatelet, P., Dzhola, A. V., Edwards, D. P., Hase, F., Kramer, I., Mahieu, E., Mellqvist, J., Notholt, J., Novelli, P. C., Rockmann, A., Scheel, H. E., Schneider, M., Schulz, A., Strandberg, A., Sussmann, R., Tanimoto, H., Velazco, V., Drummond, J. R., and Gille, J. C.: Increased Northern Hemispheric carbon monoxide burden in the troposphere in 2002 and 2003 detected from the ground and from space, Atmos. Chem. Phys., 5, 563-573, doi:10.5194/acp-5-563-2005, 2005.
Zanis, P., Ganser, A., Zellweger, C., Henne, S., Steinbacher, M., and Staehelin, J.: Seasonal variability of measured ozone production efficiencies in the lower free troposphere of Central Europe, Atmos. Chem. Phys., 7, 223-236, doi:10.5194/acp-7-223-2007, 2007.

Zbinden, R. M., Cammas, J.-P., Thouret, V., Nédélec, P., Karcher, F., and Simon, P.: Mid-latitude tropospheric ozone columns from the MOZAIC program: climatology and interannual variability, Atmos. Chem. Phys., 6, 1053-1073, doi:10.5194/acp-6-10532006, 2006.

Zellweger, C., Forrer, J., Hofer, P., Nyeki, S., Schwarzenbach, B., Weingartner, E., Ammann, M., and Baltensperger, U.: Partitioning of reactive nitrogen $\left(\mathrm{NO}_{\mathrm{y}}\right)$ and dependence on meteorological conditions in the lower free troposphere, Atmos. Chem. Phys., 3, 779-796, doi:10.5194/acp-3-779-2003, 2003.

Zellweger, C., Ammann, M., Buchmann, B., Hofer, P., Lugauer, M., Rüttimann, R., Streit, N., Weingartner, E. and Baltensperger U.: Summertime $\mathrm{NO}_{\mathrm{y}}$ speciation at the Jungfraujoch, $3580 \mathrm{~m}$ above sea level, Switzerland, J. Geophys. Res., 105(D5), 6655-6667, 2000.

Zellweger, C., Hüglin, C., Klausen, J., Steinbacher, M., Vollmer, M., and Buchmann, B.: Inter-comparison of four different carbon monoxide measurement techniques and evaluation of the long-term carbon monoxide time series of Jungfraujoch, Atmos. Chem. Phys., 9, 3491-3503, doi:10.5194/acp-9-3491-2009, 2009. 